\title{
Mean Global Ocean Temperatures during the Last Glacial Transition
}

Authors: Bernhard Bereiter*1,2,3 ${ }^{\text {, Sarah Shackleton }{ }^{1} \text {, Daniel Baggenstos }{ }^{1,2} \text {, Kenji Kawamura }}{ }^{4,5,6}$, Jeff Severinghaus ${ }^{1}$

${ }^{1}$ Scripps Institution of Oceanography, University of California San Diego, La Jolla, California 92037, USA

${ }^{2}$ Climate and Environmental Physics and Oeschger Center for Climate Research, University of Bern, 3012 Bern, Switzerland

${ }^{3}$ Laboratory for Air Pollution and Environmental Technology, Empa, 8600 Dübendorf, Switzerland

${ }^{4}$ National Institute of Polar Research, Research Organizations of Information and Systems, 10-3 Midori-cho, Tachikawa, Tokyo 190-8518, Japan.

${ }^{5}$ Department of Polar Science, Graduate University for Advanced Studies (SOKENDAI), 10-3 Midori-cho, Tachikawa, Tokyo 190-8518, Japan.

${ }^{6}$ Institute of Biogeosciences, Japan Agency for Marine-Earth Science and Technology, 2-15 Natsushima-cho, Yokosuka 237-0061, Japan.

*Corresponding Author: bereiter@climate.unibe.ch

\section{Article Summary}

Due to a lack of robust reconstructions and limited observations, little is known about the ocean temperature's long-term response to climate perturbations. While the ocean has taken up most of the 'excess' heat from the current global warming, its role in the upcoming century and beyond is uncertain. Here, using noble gases trapped in ice cores, we show that mean ocean temperature increased by $2.57+/-0.24^{\circ} \mathrm{C}$ over the last glacial transition $(20,000$ to 10,000 years ago). Our reconstruction provides unprecedented precision and temporal resolution for the integrated global ocean, in contrast to the depth-, region-, organism- and/or season-specific estimates provided by other methods. We find that mean ocean temperature is closely correlated with Antarctic temperature and has no lead or lag with atmospheric $\mathrm{CO}_{2}$, thereby confirming the important role of southern hemisphere climate for global climate trends. We also reveal an enigmatic 700-year warming during the early Younger Dryas that surpasses estimates of modern ocean heat uptake.

\section{Relevance of Mean Ocean Temperature}

Today, the global ocean takes up about $93 \%$ of the excess heat from anthropogenic activities ${ }^{1}$, which dominates the current global radiation imbalance ${ }^{2}$. Due to the heterogeneity and size of the global ocean it is difficult to precisely measure its heat content and mean ocean temperature (MOT). A large number of sensors are needed to track regional changes and derive global trends, as in the Argo float array project ${ }^{3}$. Nevertheless, this system does not yet cover a significant part of the deep ocean (depth below 2,000 m) leaving uncertainty in the MOT estimates for the current warming. For changes in MOT before Argo (started around 2,000 CE), the data basis is much weaker, as the observations were much more sparse ${ }^{1}$. Considering that the slow overturning time of the global ocean (centuries to millennia) determines the responsiveness of MOT to changing climate, much interest exists in reconstructing ocean temperatures before the first observations (ca. $1865 \mathrm{CE}$ ).

Marine proxies have produced such reconstructions on a variety of temporal and spatial scales ${ }^{4-7}$, however, the different proxies have strengths and weaknesses leading to a debate about the interpretation of the corresponding data ( ref. 4 and references in there). The difficulty lies in 
separating temperature from other effects as well as assessing a precise proxy-to-temperature transfer function because of the complex biogeochemistry behind these proxies and potential regional as well as temporal differences ${ }^{5,8}$. While trends in these proxies might be representative for the temperature trends, these issues are in particular problematic for the absolute accuracy of the corresponding temperature scale. The uncertainty of the absolute scale lies in the range of $+/-1{ }^{\circ} \mathrm{C}$ ${ }^{4,8}$, which poses a major limitation for the determination of the glacial-interglacial MOT change (about $\left.3^{\circ} \mathrm{C}\right)^{4}$.

Here we use a novel proxy for MOT introduced by ref. 9 based on measurements of inert/noble gas mixing ratios $\left(\mathrm{Kr} / \mathrm{N}_{2}, \mathrm{Xe} / \mathrm{N}_{2}, \mathrm{Xe} / \mathrm{Kr}\right)$ in ice core samples (see Methods and ref. 10 for analytical details). The data are used to reconstruct past MOT with unequalled accuracy taking advantage of the following characteristics of the ocean-atmosphere system: (i) any heat and gas exchange takes place at the ocean-atmosphere interface; (ii) there are no significant internal heat sources or sinks in the ocean ${ }^{11}$; (iii) there are no significant sources or sinks of the measured gases in the combined ocean-atmosphere system; and (iv) each gas species has a unique and well-defined temperaturedependent solubility. Therefore, a change in MOT leads to a change of the dissolved noble gas inventory in the ocean, which is in turn mirrored by an opposing change in the atmosphere without any intrinsic temporal delay/filtering (see detailed discussion in Methods). Because the atmosphere is well-mixed this method effectively integrates globally. Thus, as opposed to marine proxies, the atmospheric noble gas ratio is a purely physics-driven proxy for the global ocean heat content and MOT $^{9,11}$.

We analyzed 78 ice samples (including 10 partial to full sample rejections, see Methods) from the WAIS Divide ice core that cover the last glacial maximum (LGM) to the pre-industrial period. For the period from 22 - 8 kyr BP (kilo years before 'present' (1950 CE)) - which contains the last glacial transition (20-10 kyr BP) - a high temporal resolution of 250 years on average was obtained. Together with the rich information available from the same ice core and the excellent age control in this climate archive, our record allows unprecedented insights into the interplay between climate and MOT during a period of major climate change.

\section{Inferring MOT from Noble Gases}

In order to derive the atmospheric ratios needed for the MOT reconstruction, the raw data has to be corrected for gravitational enrichment and thermal fractionation in the firn column ${ }^{12}$. Similar to ref. 9 and 10 , we use the measured argon isotope ratio $\delta^{40} \mathrm{Ar}\left({ }^{40} \mathrm{Ar} /{ }^{36} \mathrm{Ar}\right)$ to correct the elemental ratios for the gravitational fractionation. The correction we apply assumes that the firn air column is in full thermal-gravitational equilibrium, which might not have been the case as indicated by the difference between the $\delta^{86} \mathrm{Kr}\left({ }^{86} \mathrm{Kr} /{ }^{82} \mathrm{Kr}\right.$ ) and $\delta^{40} \mathrm{Ar}$ (see Methods). This $\delta^{86} \mathrm{Kr}$ anomaly is a new phenomenon that needs to be further investigated; however, it is roughly constant over the entire record, suggesting that the potential bias is small on relative changes within the record (but might have an effect on the absolute scale - see below and Methods for more details).

The thermal fractionation correction is minor at the WAIS divide ice core site due to high accumulation rates and the gradual surface temperature changes ${ }^{13}$, which limit the temperature gradients in the firn to about $1^{\circ} \mathrm{C}$. The effects are, however, not negligible (approximately $0.25^{\circ} \mathrm{C}$ change in MOT per $1{ }^{\circ} \mathrm{C}$ thermal gradient). Therefore, we correct our data for the thermal fractionation using two independent firn column temperature scenarios which represent the range of uncertainty of this correction element (see Methods). For our analysis below we combine the two scenarios in a Monte-Carlo fashion to incorporate this uncertainty into our final best-estimate record.

To reconstruct MOT from the paleo-atmospheric $\mathrm{Kr} / \mathrm{N}_{2}, \mathrm{Xe} / \mathrm{N}_{2}$ and $\mathrm{Xe} / \mathrm{Kr}$ ratios, we use a 4-box ocean-atmosphere model based on ref. 9 and 10 (Fig. 1 and Methods). To account for changes in sea-level pressure, ocean volume and salinity, which affect the inventory of soluble gases in the 
ocean, we use the sea level record of ref. 14 (Fig. 3 b). For each gas ratio 12,000 Monte-Carlo MOT realizations are calculated that incorporate analytical uncertainties, uncertainties of the sea-level record, the degree of gas saturation, and those related to the applied firn thermal correction mentioned above (more details in Methods). We combine all realizations (36,000 in total) to a single best-estimate record (Fig. 2, red). In this way, the obtained uncertainty accounts for inconsistencies between the estimated and effective thermal fractionation factors, for biases of the single-ratio MOT records (see Methods), as well as for all known model and analytical uncertainties. Thus, our uncertainty estimate is representative for the relative changes within our MOT record. Note that the uncertainty does not account for the potential bias induced by firn air disequilibrium mentioned above. Fig. $3 \mathbf{b}$ shows a splined version of the our best-estimate record with a low cut-off frequency to not dampen sharp features in our record, however, caution is required when interpreting excursions based on single data points such as e.g. around $20 \mathrm{kyr}$ BP.

\section{Glacial-Interglacial MOT Difference}

Based on our best-estimate record we determine the MOT change from LGM to early Holocene (averaging periods marked by grey bars in Fig. 3) to $2.57+/-0.24^{\circ} \mathrm{C}$ (1-sigma). This is comparable to the estimates from marine proxies of $3+/-1{ }^{\circ} \mathrm{C}$. The major contribution to the uncertainty estimate originates from a possible change in saturation state of the gases in the ocean. Today, the deep water masses are slightly undersaturated with noble gases with respect to the water temperature ${ }^{15,16}$. During the LGM this undersaturation could have been reduced by about $50 \%$, which would cause a bias in the LGM MOT of $0.24^{\circ} \mathrm{C}$ in our best estimate record (see Methods for more details). All other sources of uncertainty are of minor or negligible importance for this part of the analysis.

Even though MOT changes are related indirectly to average sea surface temperature (ASST) changes, which are in turn related to global average surface temperatures (GAST) - both important numbers for estimates of Earth system sensitivity ${ }^{8,17-19}$ - it is not straightforward to constrain the LGM-Holocene ASST or GAST change from the MOT change we derive here. The main deep water masses such as Antarctic Bottom Water (AABW) and North Atlantic Deep Water (NADW) which represent today about $55 \%$ of the global ocean volume - are ventilated and thermally equilibrated in high-latitude areas around $60^{\circ 20,21}$. Therefore, MOT is biased towards the polar regions in its representation of ASST. Furthermore, multiple lines of evidence suggest that the glacial deep water circulation was significantly different from today, with a more stratified ocean and a larger AABW cell at the expense of the other water masses ${ }^{22-25}$. On the one hand, if one considers that surface temperature changes are amplified in higher latitudes compared to lower latitudes - a well-known climate phenomenon known as polar amplification - one could argue that our LGM-Holocene MOT change represents an upper limit of average SST change. On the other hand, it is not clear by how much the changes in ocean circulation have affected the relevant areas for global ocean ventilation ${ }^{21}$.

To explore these different aspects that link ASST and GAST to MOT, we evaluated oceanic and atmospheric temperature fields of 7 different global climate models ( 6 are part of the Paleoclimate Modelling Intercomparison Project 3 (PMIP3)) that provided such output for LGM and preindustrial conditions (see Methods). All these independent state-of-the-art climate models have different but physically consistent climatologies for the two climate states, for which reason the model ensemble spread is representative for the uncertainties of how MOT, ASST and GAST are linked. The model ensemble range of the scaling factor for $\triangle \mathrm{ASST} / \triangle \mathrm{MOT}$ and $\triangle \mathrm{GAST} / \triangle \mathrm{MOT}$ is 0.7 to 0.9 and 2.0 to 2.9 , respectively. The models generally underestimate the LGM-Holocene MOT difference (range: $0.9^{\circ} \mathrm{C}$ to $2^{\circ} \mathrm{C}$ ) relative to our results. Despite the uncertainties related to these scaling factors, they suggest that the LGM-Holocene GAST difference is between $5.1^{\circ} \mathrm{C}$ and $7.5^{\circ} \mathrm{C}$, which is roughly consistent with the estimates of ref. 8 and 19 , but challenging the low values of ref. 6 and in particular of 26. Note that most of these studies use similar PMIP climatology 
to infer GAST as we do here, however, they use surface temperature proxies that are recording local climate and are affected by ocean biogeochemistry. Due to the globally integrative and purelyphysics driven nature of the MOT proxy we present here it might be possible to better constrain such estimates in the future and narrow down some of the uncertainties related to the LGM GAST.

It is interesting to note that since the LGM about the same amount of energy has gone into MOT as into melting grounded ice (Fig. 3 b). This is not contradicting the understanding that most of the current anthropogenic warming has been taken up by the ocean even though only about $10 \mathrm{~cm}$ of sea level rise (about half of the total rise of $19 \mathrm{~cm}$ since 1900) is attributed to melting of grounded ice $^{2}$, whose latent heat equivalent is only about $3 \%$ of the total energy taken up by the ocean ${ }^{1}$. The response of melting land ice due to global warming is very much dependent on the geometry/configuration/sensitivity of the global ice sheets at a specific point in time ${ }^{27}$. Therefore, the 1:1 ratio of energy going into the ocean and melting grounded ice has to be regarded as an average over the whole last glacial transition and cannot be expected to hold for the anthropogenic warming. However, as a recent study has shown ${ }^{28}$, including ice melting is important to close also the current global energy budget and can provide new insights into the mechanism behind recent decadal global temperature variabilities.

\section{Climate-MOT Interplay}

There is no temporal uncertainty between the MOT and $\mathrm{CH}_{4}$ records (Fig. 3 g) since they were obtained from the same ice core. Atmospheric $\mathrm{CH}_{4}$ reacts quickly to changes in the northern and tropical regions (within decades) and has been measured with very high resolution and precision ${ }^{29}$. Therefore, it is an excellent time marker for the abrupt changes in northern hemisphere climate (dashed lines in Fig. 2 and 3) related to variations in the Atlantic Meridional Overturning Circulation (AMOC), that separate the climate period Heinrich Stadial 1 (HS1), Antarctic Cold Reversal (ACR) and Younger Dryas (YD) from each other ${ }^{30}$. This allows a precise comparison between MOT and the changing climate/ocean circulations that are associated with the climate periods mentioned above (Fig.3).

First, the comparison of the inflection points of MOT and abrupt changes in the $\mathrm{CH}_{4}$ record shows no lead or lag of MOT relative to these events (with the exception of the YD end, see below). In particular for the HS1-ACR transition, the temporal constraints are strong due to the high resolution of both the MOT and $\mathrm{CH}_{4}$ record. For this event we estimate the MOT inflection point to occur at $14,780+/-390 \mathrm{yr}$ BP. This is indistinguishable from the occurrence of the corresponding $\mathrm{CH}_{4}$ change at $14,580+/-80 \mathrm{yr}$ BP. This constrains any possible phase shift between $\mathrm{CH}_{4} / \mathrm{AMOC}$ change and MOT to be within a couple of centuries, at least for this point in time.

Second, the trends in the MOT record we present here are strikingly similar to those of Antarctic temperature (AAT) during the last glacial transition (Fig. 3). AAT and MOT show the same general evolution of stable temperatures during the LGM, followed by a moderate warming during HS1 (17,690 to $14,580 \mathrm{yr} \mathrm{BP})$, a cooling during the ACR (14,580 to $12,750 \mathrm{yr} \mathrm{BP}$ ), a strong warming during the YD (12,750 to $11,550 \mathrm{yr}$ BP) before reaching stable Holocene values. In fact, the YD MOT warming is finished about $500 \mathrm{yr}$ before the rapid $\mathrm{CH}_{4}$ rise at 11,550 yr BP that marks the end of the YD; The end of the YD is an anomaly to the otherwise close relationship of MOT and AAT during the last glacial transition.

During the HS1 period, MOT changes at a rate of $0.67+/-0.11 \mathrm{mK} / \mathrm{yr}$, which corresponds to an energy uptake by the ocean of $3.6+/-0.52 * 10^{21} \mathrm{~J} / \mathrm{yr}$. This is about half as much as what is estimated for the ocean heat uptake between 1997 and $2015\left(8+/-3.5 * 10^{21} \mathrm{~J} / \mathrm{yr},{ }^{1}\right)$. The ACR period is characterized by a significant cooling of the global ocean of $-0.29+/-0.13 \mathrm{mK} / \mathrm{yr}$, which translates into an energy loss of $-1.4+/-0.66 * 10^{21} \mathrm{~J} / \mathrm{yr}$. The warming from 12,750 to $12,050 \mathrm{yr} \mathrm{BP}$ (referred to as YD1) within the YD represents the strongest global ocean warming phase within our record. The MOT change rate is $2.5+/-0.53 \mathrm{mK} / \mathrm{yr}$ and the corresponding energy uptake $13.8+/$ - 
$2.9 * 10^{21} \mathrm{~J} / \mathrm{yr}$. This unprecedented MOT warming rate is $70 \%$ more than the strong warming since 1997 compared to the model ensemble mean of ref. 1 and becomes even more extreme when comparing with the last 35 years (see below). The close relation between our MOT record and AAT/AMOC changes as well as the strong warming during the YD1 are two intriguing features of our record and are discussed here in more detail.

The synchronicity of MOT and AAT during the last glacial transition is somewhat surprising because AAT (and atmospheric $\mathrm{CO}_{2}$ ) seems to lead global averaged surface temperatures (GAST) by several centuries ${ }^{6}$ (Fig. 3 f). However, this is not a contradiction because the lag of GAST relative to $\mathrm{AAT} / \mathrm{CO}_{2}$ is explained by a lag of the northern hemisphere temperatures (N-GAST) while the southern hemisphere temperatures (S-GAST) are synchronous with (or even leading) $\mathrm{AAT} / \mathrm{CO}_{2}{ }^{6}$. With MOT being a S-GAST biased parameter due to the larger volume of the ocean ventilated in this hemisphere ${ }^{20,22}$, the synchronicity of MOT and AAT/CO $\mathrm{C}_{2}$ is consistent with GAST lagging AAT/CO $\mathrm{CO}_{2}$ as found by ref. 6 . The general picture arising from this is that $\mathrm{MOT}, \mathrm{CO}_{2}$ and SGAST are changing synchronous (within the given uncertainties) and N-GAST is lagging during the last glacial transition. With the glacial atmospheric $\mathrm{CO}_{2}$ rise attributed to the release of $\mathrm{CO}_{2}$ from the southern ocean ${ }^{31}$, this suggests that (at least for this transition) the southern hemisphere climate was driving the global climate out of the glacial period and not the northern hemisphere. The similarity between AAT/AMOC and MOT could be explained such that only the waters ventilated on the high southern latitudes have a net effect on MOT. Through the well-known AMOC-related northward surface heat transport known as the bipolar seesaw mechanism ${ }^{32}$, the Southern Ocean (SO) surface temperatures increase when the AMOC is in a weak state and vice versa. These surface temperature changes may have reached the southern deep water formation areas and subsequently change the AABW temperatures, which fills a large portion of the global ocean volume. Changes in other regions might not necessarily have a net effect on MOT. This simple explanation suggests that the current ocean heat uptake could indeed be underestimated/undersampled since $\mathrm{AABW}$ forms in the $\mathrm{SO}$ and fills the bottom part of the ocean below $2000 \mathrm{~m}$, areas which are inadequately covered by observations such as the Argo float system 3 .

However, this purely SO driven explanation for the AMOC-MOT relation might be too simplistic. The basic behavior of MOT increase during a weak AMOC and vice versa is seen in the two model experiments that look into this ${ }^{11,33}$, but it is explained by changes in the low-latitudinal ocean. The change in AMOC affects the heat capacity of the low-latitudinal Atlantic, which leads to accumulation of heat in this region after a switch from a strong to weak AMOC (such as from LGM to HS1) and a release of heat in the opposite case (such as from HS1 to BA) ${ }^{33}$. This mechanism produces very similar MOT patterns and rates of change in the experiments of ref. 33 to what we find for the HS1/BA periods, providing some support for this underlying mechanism. However, the mechanism/model is not sufficient to explain the MOT pattern and rates of change during the YD, where we find a much stronger warming in a first phase (about $700 \mathrm{yr}$ ) followed by temperature stabilization. In fact, this pattern is more comparable to what ref. 11 simulate in their AMOC disturbance experiments, though the magnitude of change in these experiments is quite different. In summary, the relationship between AMOC strength and MOT is a consistent feature in the few model studies that investigate the tie between these parameters, but neither study replicates the temporal pattern or magnitude of MOT change observed in this record.

So far we have looked into the ways that changes in AMOC could affect MOT. The causality, however, may be flipped: MOT may affect the AMOC. As shown in ref. 34, changes in SO surface heat flux can affect the stability of the AMOC. If southern heat fluxes are high, the AMOC is stronger, and vice versa, because a warmer/colder SO is associated with a warmer/colder AABW which reduces/increases the density differences between NADW and AABW and, hence, increases the pull/push onto the AMOC. In fact, the two causal relations mentioned here (effect of the AMOC onto MOT and vice versa) could provide a feedback loop that explains the fluctuations of the AMOC that is characteristic for the glacial periods ${ }^{23}$ : During a weak AMOC state, the SO/AABW 
warms ${ }^{33}$ which decreases the density differences between NADW and AABW, continuously increasing the "pull" onto the AMOC. Once the "pull" becomes too large, the AMOC switches to its strong state which in turn starts cooling AABW, making it again harder for the AMOC to sustain its strength as AABW becomes denser again. In other words, the bipolar seesaw and the teleconnection between SO and AMOC together would make up a density oscillator which could - depending on the background ocean temperatures/stratification ${ }^{34}$ - be self-sustaining and not necessarily triggered by a North Atlantic surface perturbation, a popular notion about the cause behind the glacial AMOC fluctuations. This density oscillator is likely not only temperature driven but also involves salinity changes. As outlined by ref. 22, SO temperatures also affect the sea ice extent and the associated effect of brine rejection on the salinity/density of the SO waters potentially exceeds the temperature effect on AABW density by up to a factor 5 . The idea described here needs thorough testing with ocean models, and does not explain e.g. the abruptness of the AMOC changes that are characteristic to these AMOC changes in glacial times. However, it provides an alternative to the otherwise North Atlantic focused explanations for these oscillations and is in line with the MOT record presented here.

\section{Younger Dryas Warming and Summary}

The strong YD1 MOT warming is a striking element of our record and represents a clear anomaly to the otherwise strong link between MOT, AAT and AMOC, respectively. The event starts at the same time as the corresponding warming events seen in the AAT and GAST records, but MOT shows a clearly higher warming rate and reaches its Holocene level significantly earlier. The correction of our data for the firn fractionation processes is critical, but neither the stable isotope data used to derive this correction show any inconstancy nor does the uncertainty in the thermal correction have enough leverage to explain this event (see Methods). There is an unexpected change in the accumulation rate in the WAIS divide ice core from 12,000 to $11,600 \mathrm{yr} \mathrm{BP}^{35}$ which could cause weakly understood dynamic firn fractionation processes, but this event had no effect on the YD1 part of the noble gas record because the air was already trapped in the ice before the accumulation event started (uncertainty in gas vs. ice-age is only $+/-50 \mathrm{yr}^{36}$ ). Therefore, the YD1 noble gas changes found here seem to be truly atmospheric. We cannot exclude that the ocean circulation pattern has shifted rapidly from its potential glacial state ${ }^{22}$ to its modern state during the YD1 which could cause a dampening of the YD1 MOT change by up to $0.35^{\circ} \mathrm{C}$ (sum of " $\mathrm{Kr}$ and $\mathrm{Xe}$ saturation state" and "AABW volume" bias in Methods) because we currently assume a gradual change. There is no evidence that such a change happened specifically at this point in time for which reason we continue with the gradual change assumption. Nevertheless, this $22 \%$ leverage to dampen the YD1 MOT event still leaves the YD1 as an extreme event in terms of MOT warming.

The YD1 phase is associated with a strong ocean heat uptake of $1.1+/-0.23 \mathrm{~W} / \mathrm{m}^{2}$, but the greenhouse gas forcing is basically stable, the orbital forcing change is negligible, the sea-level record does not indicate any major losses of land ice/albedo ${ }^{14}$ (Fig. 3 b), and other processes rather tend to a slight negative radiative forcing ${ }^{37}$. This suggests that the YD1 MOT warming is driven by ocean dynamics rather than by radiative forcing changes. The drainage of Lake Agassiz has likely driven the AMOC changes during the YD ${ }^{37}$, however, AMOC-disturbance experiments using intermediate complexity climate models do either not reproduce the high MOT warming rate of YD1 $\left(1.6^{\circ} \mathrm{C}\right.$ in about 700 years ${ }^{33}$, or fail to sustain this high rate over the observed period ${ }^{11}$. This suggests that AMOC changes can only explain part of the YD1 MOT warming. In experiments using state-of-the-art global climate models forced by anthropogenic greenhouse gas emissions ${ }^{1}$, none of the 15 models reaches the warming rate of YD1 averaged over 1971-2005 (35 years). The maximum rate is about $1 / 4$ of the YD1 warming rate, even though the greenhouse gas radiative forcing is at least 10 times stronger than during YD1 ${ }^{38}$. In summary, this shows that the YD1 MOT warming is challenging the current understanding of global ocean temperature regulation and suggests that either current climate models generally underestimate the ability of the ocean to take up heat, or that climate conditions/drivers during the YD1 have been significantly different from the 
mentioned model experiments in a way that allows much stronger heat-uptake. Two ideas about possible conditions/drivers behind the YD1 warming are further discussed in the Methods section and are related to the strong insulation in high latitudes during YD1 (see Fig. $3 \mathbf{d}$ ) and an isolated water mass combined with a drastic change in the global ocean overturning circulation, respectively.

In summary, the MOT reconstruction for the last glacial transition we present here constrains MOT with unprecedented accuracy from a novel proxy based on noble gases in the atmosphere. The record provides unique insights into the energy budget of the currently largest energy buffer in the climate system - the ocean - and its interplay with changing climate and ocean circulation. The new insights we gain here raise questions about how the ocean regulates its temperature under variable conditions - a topic very important for future climate change -, but has not yet been studied extensively due to a lack of long term reconstructions. We describe here the general features of the data and possible explanations for them, but further work is needed using global climate models to test the hypotheses mentioned here.

\section{References}

1. Gleckler, P. J., Durack, P. J., Stouffer, R. J., Johnson, G. C. \& Forest, C. E. Industrial-era global ocean heat uptake doubles in recent decades. Nat. Clim. Chang. (2016). doi:10.1038/NCLIMATE2915

2. Stocker, T. F. et al. Climate Change 2013: The Physical Science Basis. Contribution of Working Group I to the Fifth Assessment Report of the Intergovernmental Panel on Climate Change. (2013).

3. Abraham, J. P. et al. A review of global ocean temperature observations: implications for ocean heat content estimates and climate change. Rev. Geophys. (2013).

4. Elderfield, H. et al. Evolution of Ocean Temperature and Ice Volume Through the MidPleistocene Climate Transition. Science 337, 704-709 (2012).

5. Elderfield, H. et al. A record of bottom water temperature and seawater $\delta^{18} \mathrm{O}$ for the Southern Ocean over the past $440 \mathrm{kyr}$ based on $\mathrm{Mg} / \mathrm{Ca}$ of benthic foraminiferal Uvigerina. Quaternary Science Reviews, 160-169 (2010).

6. Shakun, J. D. et al. Global warming preceded by increasing carbon dioxide concentrations during the last deglaciation. Nature 484, 49-55 (2012).

7. Shakun, J. D., Lea, D. W., Lisiecki, L. E. \& Raymo, M. E. An 800-kyr record of global surface ocean $\delta^{18} \mathrm{O}$ and implications for ice volume-temperature coupling. Earth Planet. Sci. Lett. 426, 58-68 (2015).

8. Snyder, C. W. Evolution of global temperature over the past two million years. Nature (2016). doi:10.1038/nature19798

9. Headly, M. A. \& Severinghaus, J. P. A method to measure $\mathrm{Kr} / \mathrm{N}_{2}$ ratios in air bubbles trapped in ice cores and its application in reconstructing past mean ocean temperature. J. Geophys. Res. 112, D19105 (2007).

10. Bereiter, B., Severinghaus, J. \& Kawamura, K. New Method for Measuring Atmospheric Heavy Noble Gas Isotope and Elemental Ratios in Ice Core Samples. Rapid Commun. Mass Spectrom. in review, (2017).

11. Ritz, S. P., Stocker, T. F. \& Severinghaus, J. P. Noble gases as proxies of mean ocean temperature: sensitivity studies using a climate model of reduced complexity. Quat. Sci. Rev. 30, 3728-3741 (2011).

12. Severinghaus, J. P., Sowers, T., Brook, E. J., Alley, R. B. \& Bender, M. L. Timing of abrupt 
MOT during last transition from WAIS

27 November 2017

climate change at the end of the Younger Dryas interval from thermally fractionated gases in polar ice. Nature 391, 141-146 (1998).

13. Cuffey, K. M. et al. Deglacial temperature history of West Antarctica. PNAS (2016).

14. Lambeck, K., Rouby, H., Purcella, A., Sunc, Y. \& Sambridgea, M. Sea level and global ice volumes from the Last Glacial Maximum to the Holocene. 15296-15303 (2014).

15. Hamme, R. C. \& Severinghaus, J. P. Trace gas disequilibria during deep-water formation. Deep. Res. I 54, 940-950 (2007).

16. Loose, B. et al. Estimating the recharge properties of the deep ocean using noble gases and helium isotopes. J. Geophys. Res. Ocean. 121, 5959-5979 (2016).

17. Bindoff, N. L. et al. Detection and Attribution of Climate Change: from Global to Regional. Clim. Chang. 2013 Phys. Sci. Basis. Contrib. Work. Gr. I to Fifth Assess. Rep. Intergov. Panel Clim. Chang. Chapter 10 867-952 (2013). doi:10.1017/CBO9781107415324.028

18. Knutti, R. \& Hegerl, G. C. The equilibrium sensitivity of the Earth's temperature to radiation changes. Nat. Geosci. 1, 735-743 (2008).

19. Annan, J. D. \& Hargreaves, J. C. A new global reconstruction of temperature changes at the Last Glacial Maximum. Clim. Past 9, 367-376 (2013).

20. Johnson, G. C. Quantifying Antarctic Bottom Water and North Atlantic Deep Water volumes. J. Geophys. Res. 113, 1-13 (2008).

21. Gebbie, G. \& Huybers, P. How is the ocean filled? Geophys. Res. Lett. (2011). doi:10.1029/2011GL046769

22. Ferrari, R. et al. Antarctic sea ice control on ocean circulation in present and glacial climates. PNAS 111, 8753-8758 (2014).

23. Piotrowski, A. M., Goldstein, S. L., Hemming, S. R., Fairbanks, R. G. \& Zylberberg, D. R. Oscillating glacial northern and southern deep water formation from combined neodymium and carbon isotopes. Earth Planet. Sci. Lett. 272, 394-405 (2008).

24. Sigman, D. M., Hain, M. P. \& Haug, G. H. The polar ocean and glacial cycles in atmospheric $\mathrm{CO}_{2}$ concentration. Nature 466, 47-55 (2010).

25. Bereiter, B. et al. Mode change of millennial CO2 variability during the last glacial cycle associated with a bipolar marine carbon seesaw. PNAS 109, 9755-9760 (2012).

26. Schmittner, A. et al. Climate Sensitivity Estimated from Temperature Reconstructions of the Last Glacial Maximum. Science 334, 1385-1388 (2011).

27. Levermann, A. et al. The multimillennial sea-level commitment of global warming. PNAS 110, 13745-13750 (2013).

28. Berger, A., Yin, Q., Nifenecker, H. \& Poitou, J. Earth's Future Slowdown of global surface air temperature increase and acceleration of ice melting Earth's Future. (2017). doi:10.1002/eft2.224

29. Rhodes, R. H. et al. Enhanced tropical methane production in response to iceberg discharge in the North Atlantic. Science 348, 1016-1019 (2015).

30. McManus, J. F., Francois, R., Gherardi, J.-M., Keigwin, L. D. \& Brown-Leger, S. Collapse and rapid resumption of Atlantic meridional circulation linked to deglacial climate changes. Nature 428, 834-837 (2004).

31. Anderson, R. F. et al. Wind-Driven Upwelling in the Southern Ocean and the Deglacial Rise in Atmospheric $\mathrm{CO}_{2}$. Science 323, 1443-1448 (2009).

32. Stocker, T. F. \& Johnson, S. J. A minimum thermodynamic model for the bipolar seesaw. 
MOT during last transition from WAIS

Paleoceanography 18, art. no. 1087 (2003).

33. Galbraith, E. D., Merlis, T. M. \& Palter, J. B. Destabilization of glacial climate by the radiative impact of Atlantic Meridional Overturning Circulation disruptions. Geophys. Res. Lett. (2016).

34. Buizert, C. \& Schmittner, A. Southern Ocean control of glacial AMOC stability and Dansgaard-Oeschger interstadial duration. Paleoceanography 30, 1595-1612 (2015).

35. Members, W. D. P. Onset of deglacial warming in West Antarctica driven by local orbital forcing. Nature 500, 440-444 (2013).

36. Buizert, C. et al. The WAIS Divide deep ice core WD2014 chronology \&ndash; Part 1: Methane synchronization (68-31 ka BP) and the gas age-ice age difference. Clim. Past 11, 153-173 (2015).

37. Renssen, H. et al. Multiple causes of the Younger Dryas cold period. Nat. Geosci. (2015). doi:10.1038/NGEO2557

38. Joos, F. \& Spahni, R. Rates of change in natural and anthropogenic radiative forcing over the past 20,000 years. PNAS 105, 1425-1430 (2007).

39. Parrenin, F. et al. Synchronous Change of Atmospheric $\mathrm{CO}_{2}$ and Antarctic Temperature During the Last Deglacial Warming. Science 339, 1060-1063 (2013).

40. Huybers, P. Early Pleistocene Glacial Cycles and the Integrated Summer Insolation Forcing. Science 313, 508-511 (2006).

41. Marcott, S. A. et al. Centennial-scale changes in the global carbon cycle during the last deglaciation. Nature 514, 616-619 (2014).

42. Reimer, P. et al. Intcal13 and marine 13 radiocarbon age calibration curves $0-50,000$ years cal bp. Radiocarbon 55, 1869-1887 (2013).

VIII. Supplementary Information

All reported data in the paper is available in the supplementary information. 
XI. Author Information

430 The authors declare no competing financial interests.

Correspondence to: Bernhard Bereiter

\section{Figure Legends}

Figure 1: Schematic of the 4-box model used to derive MOT, including the modern (Today) and LGM characteristics of the boxes. The shape and location of the boxes indicates roughly the meridional averaged situation in the modern ocean. Black arrows indicate the meridional circulation pattern of the two deep water masses AABW and NADW. White arrows indicate the exchange of noble gases between the boxes and the geographical area where they occur, respectively. The modern temperatures $(\mathrm{T})$, volumes $(\mathrm{V})$ and salinities $(\mathrm{S})$ of AABW and NADW are based on ref. 20 , while the parameters for the residual ocean are chosen such that the budget for the global average ocean $\left(\mathrm{T}=3.53^{\circ} \mathrm{C} ; \mathrm{S}=34.72 ; \mathrm{V}=100 \% / 1.34 * 10^{18} \mathrm{~m}^{3}\right)$ is closed. The LGM parameters are based on the scaling of volume and salinity as well as the constraints from the noble gas data (see Methods for more details).

Figure 2: MOT records relative to today derived from the individual noble gas ratios and their mix from this study. Dashed vertical lines and bottom labels mark different time periods (LGM $=$ Last Glacial Maximum; HS1 = Heinrich Stadial 1; B/A = Bolling-Allerod; YD = Younger Dryas) as in Fig. 3. Data are plotted on WD2014 agescale ${ }^{36}$. The mix MOT record (red; best estimate) is not shifted while the records based on the individual ratios are shifted as follows for better visibility: $\mathrm{Kr} / \mathrm{N}_{2}$ (orange) by $-1{ }^{\circ} \mathrm{C}, \mathrm{Xe} / \mathrm{N}_{2}$ (magenta) by $-2^{\circ} \mathrm{C}, \mathrm{Xe} / \mathrm{Kr}$ (purple) by $-3^{\circ} \mathrm{C}$. Deviations of the individual records relative to each other are found in the Methods section. The mean values and their error bars (1-sigma) include all analytical uncertainties and different scenarios as described in the Methods section.

Figure 3: Comparison of our best estimate MOT record with other paleoclimatic records for the last glacial transition. Vertical dashed lines and bottom area mark different time periods within this time window as on Fig. 2. The grey bars mark the sections used to derive the LGM-Holocene MOT difference. a: MOT change rate and corresponding global ocean heat flux derived from Monte Carlo splining of our best estimate MOT data set with 600 years cut-off frequency splines. Uncertainty band (dashed) represents the 1-sigma range of all realized Monte Carlo splines. b, red: Splined version of our best estimate data set (Fig. 2, red) using the same splining procedure as in a. Note, that caution is required when interpreting excursions based on single data points, such as e.g. around 20 kyr BP. b, light blue: Energy anomaly in the total ocean relative to today expressed in the same type of spline as in the red curve. The left y-axis is scaled such that the light blue and red curves overlap as much as possible. The remaining small difference originates from the different effect of ocean volume change onto the two parameters. Crosses indicate where the actual data points are located. b, blue: Sea-level anomaly record of ref. 14 transferred into the latent energy put into melting (grounded) ice to create the corresponding sea-level change (the LGM low corresponds to $134 \mathrm{~m}$ sea-level below today). The splining procedure is the same as above, but with a cut-off frequency of 150 years (because of higher resolution of this record) and a 2-sigma uncertainty band. The latent heat is derived by simple scaling of the sea level data by $3.45 \mathrm{e} 14$ ocean volume $\left(\mathrm{m}^{3}\right)$ change per meter of sea-level ${ }^{14}$ and the latent heat coefficient for the ice-water transition (thermal expansion contribution ( $\sim 0.6 \mathrm{~m}$ LGM to Holocene) can be neglected) $\mathbf{c}$ : Antarctic temperature reconstruction ${ }^{39}$. d: $60^{\circ}$ north and south (roughly where deep waters are formed) mean annual insolation anomaly relative to today ${ }^{40}$, which is driven by changes in obliquity and is symmetric on both hemispheres. e: Greenhouse gas forcing ${ }^{41}$. f: Reconstructed earth surface temperatures with 1sigma uncertainty band of northern hemisphere ( $\mathrm{NH}$, light blue), southern hemisphere ( $\mathrm{SH}$, dark blue), and global average (Global, black) ${ }^{6}$. g: Atmospheric $\mathrm{CH}_{4}$ measured at the WAIS divide ice core ${ }^{29} . \mathbf{h}$ : AMOC proxy ${ }^{231} \mathrm{~Pa} /{ }^{230} \mathrm{Th}$ from ocean sediment core OCE326-GGC5 recalibrated with 
IntCal13 ${ }^{30,42}$. All data is plotted on their original agescale if not otherwise noted (WDC 2014 for WAIS data ${ }^{36}$.

\section{Methods}

A) Analytical method to derive noble gas elemental and isotope ratios from ice core samples

The analytical method we used to analyze the trapped air in the ice samples is described in ref. 10. In short, about $800 \mathrm{~g}$ of ice are melted in an evacuated vacuum vessel and the released air is cryotrapped in a dip tube cooled with liquid helium. In a second step, the air is split into two subsamples and from one of them all non-noble gases are removed via a $\mathrm{Zr} / \mathrm{Al}$ getter. Then, each of these two subsamples is analyzed separately on a specific dual-inlet isotope ratio mass spectrometer. The two machines provide high-precision deviations (usually expressed in $\delta$-notation) from a standard, which is in our case the current atmospheric composition. Specifically, the two machines provide the following main isotope ratios (mass ratios): $\delta^{15} \mathrm{~N}\left({ }^{29} \mathrm{~N}_{2}{ }^{28} \mathrm{~N}_{2}\right), \delta^{40} \mathrm{Ar}\left({ }^{40} \mathrm{Ar} /{ }^{36} \mathrm{Ar}\right)$ and $\delta^{86} \mathrm{Kr}$ $\left({ }^{86} \mathrm{Kr} /{ }^{82} \mathrm{Kr}\right)$; as well as the following main elemental ratios: $\delta \mathrm{Ar} / \mathrm{N}_{2}\left({ }^{40} \mathrm{Ar} /{ }^{28} \mathrm{~N}_{2}\right), \delta \mathrm{Kr} / \mathrm{Ar}\left({ }^{84} \mathrm{Kr} /{ }^{40} \mathrm{Ar}\right)$ and $\delta \mathrm{Xe} / \mathrm{Ar}\left({ }^{132} \mathrm{Xe} /{ }^{40} \mathrm{Ar}\right)$. The atmospheric elemental ratios of $\delta \mathrm{Kr} / \mathrm{N}_{2}\left({ }^{84} \mathrm{Kr} /{ }^{28} \mathrm{~N}_{2}\right), \delta \mathrm{Xe} / \mathrm{N}_{2}$ $\left({ }^{132} \mathrm{Xe} /{ }^{28} \mathrm{~N}_{2}\right)$, and $\delta \mathrm{Xe} / \mathrm{Kr}\left({ }^{132} \mathrm{Xe} /{ }^{84} \mathrm{Kr}\right)$ used for the MOT reconstruction are derived by combining the machine elemental ratios accordingly and using the isotope ratios to correct for gravitational and thermal fractionation as described in details in section D) below.

The data set presented here was obtained over the course of three measurement campaigns in 2014 and 2015. The first campaign applied the method 1 described in ref. 10 during which 21 samples of the WAIS Divide ice core were analyzed. The results of two of the samples were fully or partly rejected due to measurement artifacts or artifacts occurring in the Bubble-to-Clathrate-TransitionZone of ice cores (see section B) below). The second and third campaign applied method 2 described in ref. 10 during which 42 and 15 samples, respectively, from the same core were analyzed. Six samples of the second campaign were partly or fully rejected for the same types of reasons as mentioned above; two rejections were required in the third campaign samples.

B) Sample rejection and the data gap from 4,000 to 7,500 years

10 out of the 78 samples we measured for this study are subject to sample rejections. For 3 of them, however, not the full set of data had to be rejected (partial rejections). Partial rejections can occur when a measurement error occurs after the sample splitting ${ }^{10}$ which then affects only the corresponding data set. Another possibility is that a minor error only affects the parameters that are most sensitive to it: e.g. a thermal gradient during the splitting process will affect $\delta \mathrm{Ar} / \mathrm{N}_{2}$ the most because of its strong thermal diffusion sensitivity ${ }^{43}$ relative to the obtained precision ${ }^{10}$. Depending on the amplitude of such an error some parameters might appear as outliers, while others do not. It is therefore important to thoroughly check all parameters individually and put them into context (if possible) of the whole record as done for the example of the Bubble-to-Clathrate-Transition-Zone (BCTZ) in ref. 10. For the first case (affecting one subsample), we have 2 such cases where the primary heavy noble gas data was lost due to a failure of the corresponding Mass Spectrometer. For the second case of single parameter outliers, we identified one case where we reject the data including Xe, but the remaining parameters are kept. These affected samples could be replaced by measuring a neighboring sample.

The full rejections affects 7 samples of which one is related to operational errors during the measurement procedure and another one to a contaminant in the sample. Also these two samples could be replaced by measuring a neighboring sample. The remaining 5 of these full rejections are related to gas fractionation in the BCTZ, which creates a data gap in our record from about 4,000 to 7,500 years $\mathrm{BP}^{10}$ that can only be filled with measurements at another core. In the BCTZ gases are 
fractionated due to gas-loss and fractionation processes between the bubbles and clathrates occurring in this zone ${ }^{44,45}$. We primarily identified this zone by inconsistencies/outliers in $\delta \mathrm{Ar} / \mathrm{N}_{2}$ with respect to $\delta^{40} \mathrm{Ar}\left({ }^{40} \mathrm{Ar} /{ }^{36} \mathrm{Ar}\right)$, a parameter known to be fractionated in the $\mathrm{BCTZ}{ }^{44}$, but also look into their consistencies with all observed isotope and element ratios ${ }^{10}$. The BCTZ is also known as the brittle ice zone ${ }^{46}$ due to the very brittle behavior of the ice core and is commonly reported as such by the drilling team. However, the way we observe the BCTZ through the gas measurements does not necessarily line up with the observation via the core quality or the appearance/disappearance of clathrates and bubbles in the ice. The reason is that at the upper end of the BCTZ some fractionation has to build up to get significant effects from the gas diffusion processes in the extracted air, and at the lower end, the gas fractionation can "tail" into the fully clathrated ice zone ${ }^{45}$. Hence, it is expected that the alterations in the gas record due to the BCTZ which we observe via the gas measurements is shifted downwards in depth compared to the zone defined by the core quality/inclusion observations, however, it is not clear to what extent. It was part of this study and ref. 10 to identify the BCTZ-affected zone for our obtained parameters.

The top end of the BCTZ-affected zone has been found between 922 and $1120 \mathrm{~m}$ depth and the bottom end between 1510 and $1572 \mathrm{~m}$ depth ${ }^{10}$, while the quality and inclusion observations find the BCTZ/Brittle Ice Zone from 520 to $1310 \mathrm{~m}$ depth ${ }^{47}$. The large shift of several hundred meters is surprising and has not been observed so far in other gas records, however, it is specific for the ice core and the gases we observe here and could also vary between different methods for the same gas species. Nevertheless, it is interesting to note that we find gas fractionation effects of the BCTZ to affect our data in a depth interval that is significantly deeper and slightly narrower than what the observations of the ice suggest.

A further quality control was done by comparing the reconstructed atmospheric $\delta^{18} \mathrm{O}\left({ }^{34} \mathrm{O}_{2} /{ }^{32} \mathrm{O}_{2}\right)$ values with the record of ref. 48. However, it turned out that this control is not very sensitive and did not uncover more outliers as already identified with the parameters mentioned above. Nevertheless, it is important to check all these parameters to ensure consistency of the great wealth of data the method provides, as many elements of this complicated method can alter the measurement ${ }^{10}$. The high quality of the record (outside of the BCTZ) is likely attributed to careful core handling and processing under cold conditions (the ice processing tent in the field was actively cooled to $\left.-25^{\circ} \mathrm{C}\right)^{49}$ and our subsamples were kept in a $-50^{\circ} \mathrm{C}$ freezers whenever possible to prevent outgassing ${ }^{50}$.

C) Potential time delays, low-pass filtering and biases in the noble gases from ice samples with respect to global ocean temperatures

Concentration/ratio changes of the most prominent gases in the atmosphere (i.e. $\mathrm{CO}_{2}$ or $\mathrm{O}_{2}$ ) are the result of a combination of complex biogeochemical processes reacting/adapting to changing climate (i.e. ref. 48 and 51). Therefore, these well-studied gases contain an intrinsic delay and/or low-pass filtering behavior with respect to climate change that dependents on the inertia of the underlying mechanisms. On the contrary, the noble gases analyzed in this study are not taking part in any biogeochemical process and their atmospheric changes are only dependent on their physical transportation in the atmosphere-ocean system. For our application here the relevant physical transportation processes are (i) the exchange between ocean and atmosphere, (ii) the mixing within the atmosphere and (iii) the transport from the atmosphere into the ice. Below we discuss these three elements in detail to show that they do not create a temporal modulation of the observed noble gases with respect to MOT.

All the heat fluxes in and out of the ocean take place the ocean-atmosphere interface. There is no internal heat source in the ocean while geothermal heating (the most potent heat source for the ocean besides the atmosphere/surface) is negligible compared to the forcing at the surface ${ }^{11}$. Hence, if the noble gas transport across the ocean-atmosphere interface is following the equilibrium 
solubility function as assumed here, for each joule going in or out of the ocean a corresponding number of noble gas molecules gets released from and dissolved in the ocean, respectively. Internal mixing of water masses with different temperatures mixes joules and noble gases in the same way. While this would lead to local solubility disequilibrium in these mixed waters due to the nonlinearity in the solubility functions, it does not affect the measured atmospheric composition as this takes place inside the ocean.

The assumption of gas equilibrium is justified because the gas transfer velocity between surface ocean and atmosphere of the observed gases lies in the range of $13-16 \mathrm{~cm} / \mathrm{h}{ }^{52}\left(3^{\circ} \mathrm{C}\right.$ water temperature, $10 \mathrm{~m} / \mathrm{s}$ wind speed) which translates into an equilibration timescale for these gases of 1-2 months with a mixed layer of $200 \mathrm{~m}$ thickness as found in polar regions (shorter equilibration in other regions). This is short enough to capture the strong seasonality in the hemispheric ocean heat fluxes as evidenced by atmospheric measurements of $\mathrm{Ar} / \mathrm{N}_{2}{ }^{53}$, and is also significantly shorter than the residence time of water parcels in the mixed layer, in particular in the Southern Ocean area, where gas equilibration is most critical ${ }^{54}$. There is a slight disequilibrium of noble gases in the deep ocean ${ }^{15,16}$, but this does not affect the relatively fast equilibration time scales of the surface ocean, however, it has implications for the absolute scale of our proxy as discussed below in section E). For these reasons, the ocean-atmosphere gas exchange does not create any delay or low-pass filtering behavior of atmospheric noble gases with respect to climate change/ocean temperature changes in our record. This is also supported by the model simulation of ref. 11 which includes physical gas exchange processes and ocean circulations in a three dimensional model. The ocean circulation perturbation experiments done in this study do not show any temporal modulation between the modelled ocean temperature and atmospheric noble gases.

Mixing within the atmosphere takes also place on timescales of months to a year for which reason the studied gas mixing ratios likely contain geospatial differences on seasonal timescales comparable to $\mathrm{Ar} / \mathrm{N}_{2}{ }^{53}$. However, these seasonal variations are smoothed in the trapped air in ice core samples because of the low-pass filtering of the stagnant firn air column through which atmospheric signals have to be transported before they are trapped in the ice ${ }^{55}$. The filter time characteristic for the WAIS divide ice core varies between 20 to 50 years ${ }^{29}$ meaning that the trapped air in the ice is an average value over these time periods. This filter characteristic is in fact exceptionally low for Antarctic ice core standards and is a result of the high accumulation rate at the site for which reason the WAIS divide ice core provides excellent temporal resolution capabilities for trapped gas in the ice. The firn filtering timescale is significantly lower than our maximum sampling rate of about 110 years and is also significantly below the 600 year cut-off frequency that we apply in the data splining. For all the reasons discussed here the noble gas records presented here contain no intrinsic temporal dampening element as what is known from other atmospheric gas records and are (within the given uncertainties and the current understanding) a direct representation of MOT. There are, however, processes that can alter the scaling between noble gases and MOT which are discussed and quantified in section D).

There is a scenario under which our noble gas data would be blind to MOT changes: if there would be a significant portion of the ocean which exchanges heat with the atmosphere completely decoupled from exchanging gas. The corresponding water masses would be characterized by disequilibrium between temperature and dissolved noble gases with the same magnitude of disequilibrium for all noble gases. Today, such waters do apparently not exist because all water masses found so far contain noble gases corresponding to their temperature ${ }^{15,16}$ (with a tendency to noble gas undersaturation which is, however, caused by fast cooling and is not characterized with the same magnitude for all noble gases; see also section D)). The glacial ocean circulation pattern suggested by ref. 22 could have favored the production of such "blind" water masses during LGM, however, it is important to note that our data would only be affected if these water masses would be completely isolated from the atmosphere while exchanging heat and before sinking into the deep ocean (conceivable if there was a gas-impermeable sea ice layer through which heat could be conducted and the waters underneath would fill the deep ocean without any atmospheric contact 
anymore). If the sea ice would be only partly/slowly permeable for noble gases or the waters would have had a very short exposure time with the atmosphere (expected if polynya were as important for deep water formation as today ${ }^{56}$ ), the "blindness" would not work anymore. As soon a slight exchange of gases would happen, $\mathrm{Kr}$ would come closer to equilibrium as Xe because of the faster equilibration time of $\mathrm{Kr}$ ( similar concept as behind the fast cooling effect ${ }^{15}$ ). Under such a situation our data would show a discrepancy between the MOT signal in $\delta \mathrm{Xe} / \mathrm{N}_{2}$ relative to $\delta \mathrm{Kr} / \mathrm{N}_{2}$ (because we assume constant equilibration over time; see also section D)) and, hence, be indicative for such a process (which is not the case). This scenario of $100 \%$ decoupling for a large portion of the ocean is conceivable under a snow ball earth scenario, but seems very unrealistic and hypothetical for the LGM situation, also because there is no indication that deep waters would form in such a way, but further studies with state-of-the art climate models are needed to rule out these unrealistic but not excludable effects. Note, that if LGM ocean had such a "blind" water mass, the transition from "blind" to "not blind" would have needed to happen immediately because an "in-between" state should appear as a phase of discrepancy between MOT from $\delta \mathrm{Xe} / \mathrm{N}_{2}$ and $\delta \mathrm{Kr} / \mathrm{N}_{2}$ (which is not the case).

D) Inferring atmospheric noble gas ratios from the raw data

The heavy noble gas ratios we obtain from the ice core samples are highly fractionated with respect to the atmospheric value, mainly due to gravitational fractionation in the static firn air column at the top of an ice sheet, below which the air is trapped in the ice. The depth of this firn column changes over time and is influenced - among others - by the local snow accumulation rate and temperature 57 . The effective firn air depth at a specific point in time can be "measured" by analyzing stable gas isotope ratios of $\mathrm{N}_{2}\left(\delta^{15} \mathrm{~N}\right), \operatorname{Ar}\left(\delta^{40} \mathrm{Ar}\right), \mathrm{Kr}\left(\delta^{86} \mathrm{Kr}\right)$ and $\mathrm{Xe}\left(\delta^{132} \mathrm{Xe}\right)$. By combining these ratios it is also possible to resolve the minor thermal and kinetic fractionation processes that might have occurred $^{58}$. The conditions required for kinetic fractionation to occur - as it is described in ref. 58 (very low accumulation rate, low temperature) - do not apply to the WAIS divide ice core drill site 13,36 , for which reason this effect is not considered in our calculations and we only consider gravitational and thermal fractionation. With the method used in this study we obtain the atmospherically stable ratios of $\delta^{15} \mathrm{~N}\left({ }^{29} \mathrm{~N}_{2} /{ }^{28} \mathrm{~N}_{2}\right), \delta^{40} \mathrm{Ar}$ and $\delta^{86} \mathrm{Kr}\left({ }^{86} \mathrm{Kr} /{ }^{86} \mathrm{Kr}\right)$ with a precision suitable to resolve the thermal and gravitational fractionation processes ${ }^{10}$.

In theory - knowing all the air fractionation processes occurring in the firn column - the differences between the measured isotope ratios can be used to reconstruct the thermal fractionation component using the well-known thermal diffusivity parameters ${ }^{58,59}$. Since we have three isotope ratio pairs but one fractionation effect that should affect these values, the system is over-determined and we can check whether it is consistent for all possible combinations. However, any combination including $\delta^{86} \mathrm{Kr}$ to determine the thermal component results in unrealistic constant gradients of roughly $1.5^{\circ} \mathrm{C}$ to $2^{\circ} \mathrm{C}$ during the LGM and Holocene periods, when the gradients have to be close to zero due to the stable surface temperatures ${ }^{13}$. About the same constant offset is found during the transition compared to the modelled gradient of ref. 36. If $\delta^{15} \mathrm{~N}$ and $\delta^{40} \mathrm{Ar}$ is used, the thermal component is in rough agreement with the expectations through the whole record. We have thoroughly tested our method for possible analytical artifacts that could fractionate/contaminate $\delta^{86} \mathrm{Kr}$, but could not find any indication for such an artifact. Also, if such an artifact would have been at work, we would correct for it to a large extent since we reference our ice sample measurements to modern air samples that are measured on the concept of identical treatment ${ }^{10}$.

In order to circumvent $\delta^{86} \mathrm{Kr}$ in a first step, we use an independent scenario of firn temperature history based on ref. 36 . After applying this thermal scenario to the data we follow the approach of ref. 9 and use $\delta^{40} \mathrm{Ar}$ to obtain the gravitational correction component for all other elements. $\delta^{40} \mathrm{Ar}$ has the smallest analytical uncertainty per mass unit (1.5 per meg on average) and hence, provides the highest possible accuracy for this largest - but well-defined - correction factor. The isotope data which are corrected based on this approach (ED Fig. 1) show nicely that $\delta^{86} \mathrm{Kr}$ is depleted relative to $\delta^{15} \mathrm{~N}$ and $\delta^{40} \mathrm{Ar}\left(\mathrm{Kr}\right.$-anomaly), which is the reason why the thermal gradients based on $\delta^{86} \mathrm{Kr}$ 
mentioned above turn out wrongly. We believe this $\mathrm{Kr}$-anomaly is a true signal in the trapped ice and it is probably caused by a firn fractionation mechanism unknown so far, but it needs further investigations from other sites to better understand the mechanism behind.

The Kr-anomaly seems mainly to consist of a fairly constant offset relative to the other isotope of 56 per meg without any obvious trends and changes over time (Fig. S1). This indicates that the underlying mechanism is fairly stable over time, for which reason we correct the $\delta^{86} \mathrm{Kr}$ raw data by this average offset. If we use the corrected $\delta^{86} \mathrm{Kr}$ values and compare the thermal gradients based on the different isotope pairs again as mentioned above, the results are now consistent with each other (the gradients involving $\delta^{86} \mathrm{Kr}$ do now provide realistic and comparable values as the values based on $\delta^{15} \mathrm{~N}$ and $\delta^{40} \mathrm{Ar}$ for the whole record period). Therefore we derived a second scenario for firn temperature gradients based on the measured isotopes (including the $\delta^{86} \mathrm{Kr}$ correction) by averaging the gradients derived from the three possible isotope pairs (see ED Fig. 1, b). This measurement based scenario is independent of the first model based scenario of ref. 36, which together represent the uncertainties associated with the thermal correction component for our study. We account for this uncertainty in our final MOT record by combining the 3,000 Monte-Carlo MOT realizations of each scenario and propagate this uncertainty element into our final record (see more details in section E) below). In general, the uncertainty associated with this thermal correction is comparable to the one originating from the analytical uncertainties. The analytical uncertainties translate into about $0.2^{\circ} \mathrm{C}$ uncertainty in MOT (see section C) while the effect of the two scenarios onto our MOT estimate is within about $0.25^{\circ} \mathrm{C}$ (corresponding to a $1^{\circ} \mathrm{C}$ firn temperature gradient difference of the scenarios).

We cannot exclude that the underlying mechanism of the Kr-anomaly also affects to some extent the gas ratios we use to reconstruct MOT $\left(\delta \mathrm{Kr} / \mathrm{N}_{2}, \delta \mathrm{Xe} / \mathrm{N}_{2}, \delta \mathrm{Xe} / \mathrm{Kr}\right)$. As seen in ED Fig. 2 , the reconstructed atmospheric noble gas ratios are depleted during the Holocene period, which translates into an average Holocene MOT of $-0.36^{\circ} \mathrm{C}$ below present as seen in our MOT record in the main article (Fig. 2). This Holocene MOT "offset" is more than the observed ocean warming since the industrialization ${ }^{1}$ and, hence, would suggest that there was significant MOT warming already before the industrialization. This "offset", however, could also be an artifact as the mechanism behind the $\mathrm{Kr}$-anomaly could also deplete $\delta \mathrm{Kr} / \mathrm{N}_{2}, \delta \mathrm{Xe} / \mathrm{N}_{2}$ and $\delta \mathrm{Xe} / \mathrm{Kr}$. Since the $\mathrm{Kr}$ anomaly seen in ED Fig. 1 is fairly constant over time, the effect on $\delta \mathrm{Kr} / \mathrm{N}_{2}, \delta \mathrm{Xe} / \mathrm{N}_{2}$ and $\delta \mathrm{Xe} / \mathrm{Kr}$ is also expected to be constant over time, for which reason we argue that the mechanism behind the $\mathrm{Kr}$-anomaly creates - if at all - a constant bias to our MOT record of maybe $-0.36^{\circ} \mathrm{C}$, but does not change the relative changes within our record. Therefore, relative changes such as the HoloceneLGM MOT difference or the MOT trends of the different periods, are not affected by this potential bias and represent the effective changes in MOT. However, the readers have to be careful in interpreting the absolute values we derive from our records due to the potential bias described here. Nevertheless, we do not apply any offset correction to our MOT record, as we do not feel confident to do so under the current knowledge.

Besides the fact that the conditions at the WAIS divide site do not fit the conditions required for kinetic fractionation as described in ref. 58, we tested this model and interpreted the Kr-anomaly as caused by kinetic fractionation and scaled it accordingly to the elemental ratios. The corresponding elemental ratios suggest the MOT of late Holocene to be warmer than today by about $0.25^{\circ} \mathrm{C}$ and inconsistent MOTs based on the different ratios for the LGM period. Accordingly, the mechanism behind our gas fractionation we find here has to be somewhat different to kinetic fractionation.

One way to look at the $\mathrm{Kr}$-anomaly is that the heavier $\mathrm{Kr}$ - and therefore also slower diffusing gas in the firn air column - deviates from the lighter $\mathrm{N}_{2}$ and Ar isotopes towards a smaller gravitational enrichment. This could be related to the relatively fast transformation of the WAIS divide firn air column which could lead to disequilibrium in the firn air such that the slow diffusing gases would not be able to "catch up" with the fast downward advection of the ice matrix. This effect would be stronger the slower the gases can diffuse through the air, which is in first order related to the weight 
of the molecule and hence, the reason why $\mathrm{N}_{2}$ and Ar would be less affected than the heavier gases like $\mathrm{Kr}$ and $\mathrm{Xe}$. By using the isotopes of a light molecule to correct for gravity $\left(\delta^{40} \mathrm{Ar}\right.$ in our case) the gravitational component of the heavier molecules might be overestimated. This would be consistent with the depletion in the reconstructed atmospheric $\delta^{86} \mathrm{Kr}$ (ED Fig. 1 a), and potentially also $\delta \mathrm{Kr} / \mathrm{N}_{2}, \delta \mathrm{Xe} / \mathrm{N}_{2}$ and $\delta \mathrm{Xe} / \mathrm{Kr}$. If this would be the case, however, we would expect an even stronger "anomaly" for Xe-isotopes $\left(\delta^{132} \mathrm{Xe}\left({ }^{132} \mathrm{Xe} /{ }^{129} \mathrm{Xe}\right)\right)$ as for $\mathrm{Kr}$-isotopes (about factor 2 based on the diffusivity in air/total mass). For the data obtained in the last campaign (see section A) ) we changed the mass spectrometer method such that we were able to obtain $\delta^{132} \mathrm{Xe}$ (not shown here), with a significantly worse precision than $\delta^{86} \mathrm{Kr}$, though ${ }^{10}$. The data indicates no anomaly for $\delta^{132} \mathrm{Xe}$ which is against the expectations, but the data is sparse and further work is needed to rule this out.

That a $\mathrm{Kr}$-anomaly (or $\delta^{86} \mathrm{Kr}_{\text {excess }}$ ) is indicative for disequilibrium effects in the firn air column is nicely shown by the firn air transport modelling study of ref. 60 . The model, however, currently lacks experimental support, for which reason further firn air studies at different sites with different firn transformation characteristics are needed. For our purposes, such work would also need to include the effects on the heavy noble gases (isotopes and mixing ratios), in particular $\delta \mathrm{Kr} / \mathrm{N}_{2}$, $\delta \mathrm{Xe} / \mathrm{N}_{2}$ and $\delta \mathrm{Xe} / \mathrm{Kr}$. This has the potential to significantly reduce the current uncertainty of our MOT data, both on the absolute and relative scale.

\section{E) Box model to infer MOT}

To derive MOT from the heavy noble gas data, a box model is used as described in ref. 10. The basic assumption in the model is that $\mathrm{N}_{2}, \mathrm{Kr}$ and Xe are conserved in the ocean-atmosphere system and that these gases are in solubility equilibrium state between the two reservoirs. Hence, any change in ocean temperature changes the well-defined equilibrium state of the noble gases. Since the solubilities of the individual gases are not equally sensitive to water temperature changes, the ocean temperature change leads to a change in atmospheric mixing ratio, which can be observed with ice cores. Here, the model is used backwards, using the measured atmospheric ratios as input and derive the corresponding MOT by iteration. We use the same solubility functions as used in ref. 15 ( 61 for $\mathrm{N}_{2}, 62$ for $\mathrm{Kr}$, and 63 for Xe) with the same $2 \%$ correction for the Xe solubility function.

The first rough validation of this simple box model comes from the work of ref. 9, which showed an agreement of MOT derived from their noble gas ratios measurements in ice cores with the MOT independently derived from ocean sediment core proxies. Furthermore, the simple box model has been tested against a climate model with intermediate complexity ${ }^{11}$ and also showed no significant difference between the two models despite the large complexity difference. The same study also confirmed that the only non-surface heat source for the ocean - geothermal heating - is too small to significantly affect the noble gas-MOT relation. However, in study 11 also a sea ice gas exchange effect is implemented which resulted in quite different noble gas-MOT relationships as for the nonsea-ice case. Based on the new noble gas data of this study, we can now conclude that their sea-ice effect is overestimated as the corresponding $\delta \mathrm{Xe} / \mathrm{N}_{2}$ scaling would suggest unrealistic low MOT for LGM at least $4{ }^{\circ} \mathrm{C}$ below today (our $-4 \%$ value for LGM is not anymore covered by their results).

Due to the significantly higher quality of the noble gas data presented in this study, smaller effects not considered in the first work by ref. 9 can become relevant. Therefore, we implemented and tested different model elements to assess all possible sources of uncertainties within our box model. An overview of the different elements is shown in Table S1 including the corresponding effects onto the LGM-Holocene MOT difference. The effects have been derived by successively implementing the elements from top to bottom of the table.

The most minimalistic model consists only of one ocean and one atmosphere box and uses only the measured noble gas ratios $\left(\delta \mathrm{Kr} / \mathrm{N}_{2}, \delta \mathrm{Xe} / \mathrm{N}_{2}\right.$ or $\left.\delta \mathrm{Xe} / \mathrm{Kr}\right)$ to infer MOT. This model setting suggests the LGM MOT to be roughly $-2.0^{\circ} \mathrm{C}$ colder than the Holocene, which seems too low compared to the -2.5 to $-3.5^{\circ} \mathrm{C}$ suggested by sediment core proxies and model studies ${ }^{4,5,7,11}$. Nevertheless, we 
can assess the uncertainties of our MOT estimate within this minimalistic model. The only source of uncertainty here is the analytical uncertainty which we propagate into the total MOT uncertainty using 3000 Monte-Carlo simulations (3000 realizations of MOT values while changing the noble gas ratios within their analytical uncertainties). The corresponding MOT uncertainty is on average $+/-0.26^{\circ} \mathrm{C}$ for $\delta \mathrm{Kr} / \mathrm{N}_{2},+/-0.15^{\circ} \mathrm{C}$ for $\delta \mathrm{Xe} / \mathrm{N}_{2}$, and $+/-0.17^{\circ} \mathrm{C}$ for $\delta \mathrm{Xe} / \mathrm{Kr}$, respectively, comparable to what is reported in ref. 10 for the individual methods.

As ref. 9 already pointed out, sea-level change (SLC) has a significant effect on the noble gas distribution in the ocean-atmosphere system due to the associated changes in ocean volume, ocean salinity and sea surface pressure (SSP). Salinity and SSP affects the solubility equilibrium state and the ocean volume defines the total noble gas storage capacity of the ocean. In the work here we use the SLC record from ref. 14 to derive these elements. Implementing the SLC effects increases the LGM-Holocene difference by $0.5^{\circ} \mathrm{C}$ with the largest contribution by the volume effect and the other two effects roughly compensating each other (see ED Tab. 1). The uncertainty of the SLC record is also propagated into our total MOT uncertainty estimate; however, its contribution is below $10 \%$ of that of the analytical uncertainty.

The two elements included so far correspond to what has been implemented in the previous works already. We now investigate further elements that potentially have a significant effect on our MOT reconstruction.

The colder glacial climate is known to be dryer than the interglacial/modern climate due to the lower water content. A lower water content also means a lower total mass of the atmosphere and hence, a lower average SSP. We estimate this effect using the current atmospheric $\mathrm{H}_{2} \mathrm{O}$ content of about $2.5 \%{ }^{64}$ and a Clausius-Clapeyron relation of atmospheric $\mathrm{H}_{2} \mathrm{O}$ content and temperature ${ }^{65}$ while taking our MOT differences relative to today as the effective surface temperature change. This approach might slightly underestimate the effective $\mathrm{H}_{2} \mathrm{O} / \mathrm{SSP}$ change as the average surface temperature change might have been slightly larger ${ }^{6,66}$, however, considering the small effect on the MOT reconstruction and the uncertainties related to such global surface temperature estimates, this approach is justified. For the sake of completeness, we implemented a linear change of this effect from LGM to the beginning of the Holocene in our final MOT record.

The majority of the ocean volume gets its temperature and noble gas imprint, respectively, in the high latitudes around Antarctica where the largest portion of the deep water is formed ${ }^{21}$. In these regions the average SSP is slightly lower by about $3 \%$ compared to the average ocean surface ${ }^{67}$. We therefore assume a time-independent offset of the effective SSP by $3 \%$ to calculate the solubility equilibrium state in our box model. This slightly reduces the noble gas amounts dissolved in the ocean and causes the noble gas ratios to be less sensitive to MOT changes. Hence, this effect requires a slightly lower LGM temperature of $-0.05^{\circ} \mathrm{C}$ to compensate for the reduced sensitivity. Regional SSP changes between glacial and interglacial climate are simulated to be in the range of a few $\mathrm{hPa}{ }^{68}$ which is 1-2 order of magnitude smaller than the global SSP effect from changing sealevels. Therefore we can assume this pressure bias to be time-independent.

As shown by ref. 15 and 16, deep waters today are slightly undersaturated in $\mathrm{Kr}$ and Xe with respect to the water temperature. This phenomenon is explained by the strong cooling rate these waters experience before they sink into the deep ocean, preventing the noble gases to fully equilibrate with the waters before they $\operatorname{sink}^{15}$. The observed undersaturation is roughly $2 \%$ for Xe and $1.3 \%$ for $\mathrm{Kr}$, respectively. Due to the significant differences expected in the glacial deep water circulations compared to today ${ }^{22}$, it is possible that this undersaturation pattern was different for glacial periods. As the general overturning of the deep circulation is expected to have been slower, it is likely that the cooling rate was smaller in glacial times and, hence, the undersaturation smaller. The most extreme case - where noble gases were in full equilibrium in glacial times - leads to unrealistically large discrepancies between the MOT derived from the different ratios. The change of undersaturation that keeps MOT differences roughly within the allowed uncertainty range is 50\% (meaning that Xe undersaturation at LGM could have been $1 \%$ and $\mathrm{Kr}$ accordingly). This causes the 
825 LGM temperature derived from the different ratios to be up to $0.4^{\circ} \mathrm{C}$ warmer as with a constant undersaturation (Xe/Kr being most sensitive followed by $\mathrm{Xe} / \mathrm{N}_{2}$, and almost no effect for $\left.\mathrm{Kr} / \mathrm{N}_{2}\right)$. Since the effective change in undersaturation is unknown, we calculate MOT realizations for the case with constant undersaturation at all times and a 50\% change (linear) over the course of the LGM-Holocene transition (17,900 to $11,550 \mathrm{yr}$ BP) and combine the two scenarios for our bestestimate record. This leads to a slight shift of the average MOT towards warmer temperatures and an increase in the uncertainty range for the earlier part of the record (see also LGM-Holocene MOT change estimate below).

Antarctic Bottom Waters (AABW) and North Atlantic Deep Waters (NADW) - which together represent more than $50 \%$ of the global ocean volume today and likely have occupied even more in glacial times ${ }^{22}$ - have different characteristics with regard to temperature and salinity (see also Fig. 1). Using only one ocean box in our model as done so far implies that the global temperature distribution in the ocean was the same as today and that all water masses changed their temperature equally. However, $\mathrm{AABW}$ is $-0.88^{\circ} \mathrm{C}$ cold today ${ }^{20}$ and its cooling potential is only about $1.2^{\circ} \mathrm{C}$ before it reaches the freezing point of sea water $\left(-2^{\circ} \mathrm{C}\right)$, which is not enough to fulfil the constraints on MOT during LGM from different lines of evidence (noble gas record here, ref. 9 and 4). Just by this simple consideration it is obvious that the LGM ocean temperature pattern must have been significantly different compared to today. To account for this aspect we split the ocean box in three boxes representing AABW, NADW and all other waters (RES). We set the temperature, volume and salinity of AABW and NADW according to ref. 20 (AABW: $-0.88^{\circ} \mathrm{C}, 35 \%$ of total ocean volume, 34.641 PSS; NADW: $2.3^{\circ} \mathrm{C}, 20 \%$ of total volume, 34.886 PSS) and set the RES ocean such that the averaged ocean corresponds to the today average conditions $\left(3.53^{\circ} \mathrm{C}, 1.34 \mathrm{e} 18 \mathrm{~m}^{3}, 34.72 \mathrm{PSS}\right){ }^{69}$. In a first experiment we change the temperatures of the different volumes equally as long AABW does not reach $-2^{\circ} \mathrm{C}$. If this happens $\mathrm{AABW}$ temperature is set to $-2^{\circ} \mathrm{C}$ (non-freezing) and the remainder of the cooling is compensated by the other water masses to equal shares. This requires a lower LGM MOT of $-0.2^{\circ} \mathrm{C}$ due to the non-linearity of the solubility functions and gives a sense of how strong the effect of a changing temperature distribution can be on our MOT reconstruction.

The non-freezing AABW experiment described above follows a somewhat artificial path of the ocean temperature/volume distribution. A more realistic scenario is that AABW volume was larger in glacial times, similar to what ref. 22 describes. We use a scenario in which AABW during LGM was $40 \%$ bigger compared to today and shrank linearly over the course of the LGM-Holocene transition (17,900 to $11,550 \mathrm{yr} \mathrm{BP})$ to the current situation found in ref. 20 . We choose the $40 \%$ because it roughly compensates the reduced AABW cooling/warming potential with its change in volume on the expense of the other (warmer) water masses. This more realistic (but still arbitrary) scenario reduces the effect of a change in the temperature distribution on the LGM-Holocene MOT by half to $-0.1^{\circ} \mathrm{C}$.

We use this three ocean box model version including all elements and the AABW volume change scenario described so far for our MOT reconstructions shown in the main article. The analytical uncertainties and uncertainties of the SLC record are propagated to our MOT estimate creating 3,000 Monte-Carlo MOT realizations for each data point. The same procedure is done using the two thermal correction scenarios and undersaturation scenarios described earlier. This results in 12,000 MOT record realizations for each ratio and 36,000 MOT record realizations in total. Our bestestimate record is derived based on all these realizations, which provides an objective representation of all uncertainty elements discussed here. For our LGM-Holocene MOT change estimate (see averaging periods in Fig. 3) we also use all these realizations while we interpret the propagated measurement and the SLC uncertainties as of stochastic nature and treat them as normally distributed uncertainties. However, the uncertainty introduced by the $\mathrm{Xe}$ (and $\mathrm{Kr}$ ) undersaturation effect we treat as non-stochastic as it represents equally likely scenarios. This source of uncertainty represents the largest contribution to the overall uncertainty and with this approach we find a LGMHolocene MOT difference of $2.57+/-0.24^{\circ} \mathrm{C}$.

In ED Tab. 1 we list three more elements that are not included in our MOT records, but are 
discussed here for completeness. As described in ref. 22, the glacial ocean circulation might have been characterized by a $\sim$ PSS saltier AABW cell due to missing fresh water input from melting sea ice in the Southern Ocean. As the salt content can be assumed to be conserved in the ocean on these timescales, the additional salt in AABW has to be provided by NADW and RES. Due to the salinity dependency of the solubility functions, such a salinity redistribution leads to a different weight of the differently warm water masses in the MOT reconstruction. We tested this effect by a salinity anomaly of 1PSS applied to our AABW cell (compensated by NADW and RES by equal shares) and find a small effect of only $-0.02^{\circ} \mathrm{C}$ on the LGM MOT estimate.

Another aspect we test is the potential bias caused by a large floating ice shelf. Noble gases are basically only dissolving in the liquid phase of the ocean but the SLC record does not capture the corresponding liquid ocean volume change as opposed to ice that is stored on land. We assume an ice shelf with the extent of the modern winter sea-ice around Antarctica and a thickness of $200 \mathrm{~m}$. This seems gigantic as we do not know of any evidence that such a large ice shelf could have existed. The effect of such an ice shelf on the LGM MOT estimate would only be $-0.1^{\circ} \mathrm{C}$ and shows that this potential bias is also of minor relevance.

The last row in ED Tab. 1 shows the effect of the applied 2\% correction of the Xe solubility function compared to the case if we would not apply this correction. Due to mass conservation of the noble gases in the model, this temperature independent change in the solubility function of Xe leads to a slight change in the MOT sensitivity of the ratios including $\mathrm{Xe}\left(\mathrm{Xe} / \mathrm{N}_{2}\right.$ and $\left.\mathrm{Xe} / \mathrm{Kr}\right)$. The effect onto the LGM MOT estimate, however, would only be $0.04^{\circ} \mathrm{C}$ and $0.07^{\circ} \mathrm{C}$, respectively, showing that the results presented here are not significantly affected by this existing uncertainty in the $\mathrm{Xe}$ solubility. $\mathrm{Kr}$ is about a factor two less soluble in sea water compared to Xe and the solubility function of $\mathrm{Kr}$ is better constrained as of $\mathrm{Xe}^{15}$. For these reasons, the effect on the LGM MOT estimate of the uncertainty in the $\mathrm{Kr}$ solubility function is much smaller as what is shown for Xe in ED Tab. 1 and can therefore be neglected.

\section{F) Scaling MOT to surface temperatures based on global climate models}

MOTs are set by surface ocean temperatures, which in turn are related to global surface temperatures. The connection between surface and ocean interior temperature changes is, however, also dependent on the climatology (polar amplification, ocean circulations, location of deep water formation areas, etc.) which is different for glacial and interglacial periods. The constraints on the glacial climatology are fairly weak and the realization of such climatology within a climate model can be very different from model to model. Therefore, we use several independent climate models that provide climatology for glacial and interglacial conditions and calculate the scaling factors from MOT to Average Sea Surface Temperature (ASST) and Global Average Surface Temperature (GAST) changes, respectively ( $\triangle \mathrm{ASST} / \Delta \mathrm{MOT}$ and $\Delta \mathrm{GAST} / \Delta \mathrm{MOT}$ in ED Tab. 2).

\section{Such glacial-interglacial climate model experiments are part of the Paleoclimate Modelling} Intercomparison Project (PMIP), which can be accessed openly via one of the Coupled Model Intercomparison Project (CMIP) data nodes. All results found in ED Tab. 2 are based on model output from the PMIP3 project (ensemble: r1i1p1; see ref. 70 for more details about the CMIP5/PMIP3 experiments), with the exception of the Bern3D model results which were derived specifically for this study. From the PMIP3 project results we used following variables from the LGM and Pre-industrial Control (PiC) experiments: (i)global averaged sea water potential temperature (thetaoga), (ii) sea water potential temperature (thetao), and (iii) near surface air temperature (tas). Where available, we averaged the thetaoga data to derive MOT. If only thetao was available (3D field) we averaged over the time dimension covered by the corresponding data set (12 months) and then over the space dimension while weighting the cell values by the corresponding cell volumes. ASST was calculated by first filtering all surface cells in thetao that are covered by more than $50 \%$ with sea ice, followed by the same temporal and spatial averaging as done for MOT. Therefore, our ASST values represent the open ocean surface temperatures 
excluding the areas covered by sea ice, where the heat exchange with the atmosphere is negligible and the surface ocean temperature is set to freezing temperature of the corresponding water (dependent on salinity). GAST was calculated by averaging the tas fields (2D field).

The results in ED Tab. 2 show that the LGM-Holocene MOT difference varies strongly from model to model mainly due to discrepancies in the LGM values. This shows that the models provide quite different climatologies in particular for the LGM conditions. Therefore the range of these model results can be interpreted as by how much different climatologies can affect the scaling factor between the globally averaged parameters calculated here. The $\triangle \mathrm{ASST} / \Delta \mathrm{MOT}$ scaling factor varies from 0.67 to 0.89 with an ensemble average of 0.80 . The $\Delta \mathrm{GAST} / \Delta \mathrm{MOT}$ scaling factor varies from 1.96 to 2.92 with an ensemble average of 2.50 .

In general, the models underestimate the MOT difference between LGM and Holocene with an ensemble average of $1.60^{\circ} \mathrm{C}$ and a range from $0.92^{\circ} \mathrm{C}$ to $1.95^{\circ} \mathrm{C}$, which raises the question whether the large spread of the scaling factors is correlated to the absolute LGM-Holocene MOT difference and, hence, may contain a bias. However, there is no correlation between the absolute LGMHolocene MOT difference and the scaling factors, for which reason any possible bias in these scaling factors is believed to lie within the model spread.

\section{G) Hypothesis behind the Younger Dryas MOT anomaly}

As discussed in the main article, our MOT record shows a phase of outstanding strong and fast warming during the first half of the Younger Dryas (referred to as YD1) for which we discuss here two ideas of the underlying mechanisms.

One condition that might underlie the strong MOT warming/heat uptake during YD1 could be the strong insolation in high latitudes associated with the phase of high obliquity around YD1 (Fig. 3). In the latitudes where deep waters are formed, the local annual averaged heat flux was about 1.5 $\mathrm{W} / \mathrm{m}^{2}$ higher than i.e. during LGM. The additional heat flux could have led to an increased warming of surface waters near the deep water formation areas during the summer seasons, which would have then been transported into the deep ocean during the winter seasons, when deep water formation mainly occurs. The pattern of the YD1 warming, however, is not consistent with the gradual insolation change, requiring additional processes at work. For the period before the YD1 warming and its abrupt start, the change in AMOC state can provide such an explanation: before the YD1 the strong AMOC state pulls the warm waters towards the north preventing the deep (southerly ventilated) ocean to warm. The collapse/weakening of the AMOC at the beginning of the YD1 stopped this northward heat pull and, thus, triggers the rapid YD1 warming. But for the end of the YD1 warming, which occurs significantly before the end of the YD when the AMOC accelerates again, the AMOC cannot serve as explanation anymore and some other process would be required. Note, that these orbital driven heat flux changes are fairly small with regard to the baseline flux of about $234 \mathrm{~W} / \mathrm{m}^{2}$ (today). Hence, they might have been only of minor importance for the YD1 MOT anomaly.

Another hypothesis that could explain the MOT pattern during the YD is that a cold, isolated water mass was ventilated during YD1. This water mass would have been ventilated the last time several millennia earlier, for example during the cold LGM, and only the push of the YD onset (collapse of $\mathrm{AMOC}^{30}$ ) would have brought this cold water up to the surface to equilibrate. The end of YD1 would then mark the point in time when this water mass was fully ventilated and, hence, this scenario would be able to provide an explanation for the stalled warming before the AMOC acceleration. Such a drastic change in ocean ventilation could be explained with a switch from a glacial ocean circulation mode to a modern/interglacial mode as mentioned in the main article. Multiple lines of evidences suggest the existence of such different ocean circulation modes ${ }^{22-25}$, and in the case of the shift from interglacial to glacial mode, the "MIS 5-4 transition" around 70,000 years BP has been suggested as such ${ }^{24,25}$. The YD1 could be the counterpart of the MIS 5-4 
transition, providing a relatively sharp definition of the last glacial period from an ocean circulation perspective.

$$
\text { XIV. Data availability }
$$

All relevant data from the ice samples (noble gas elemental and isotope ratios) and the corresponding reconstructed mean ocean temperatures are available in the supplementary information.

\section{XV. $\quad$ Code availability}

The ocean box model including the Monte-Carlo code (Matlab) is available from the corresponding author on request "as is". Note that the ocean box model details can also be found in ${ }^{11}$ and ${ }^{10}$.

\section{Methods References}

43. Severinghaus, J. P., Grachev, A., Luz, B. \& Caillon, N. A method for precise measurement of argon 40/36 and krypton/argon ratios in trapped air in polar ice with applications to past firn thickness and abrupt climate change in Greenland and at Siple Dome, Antarctica. Geochim. Cosmochim. Acta 3, 325-343 (2003).

44. Kobashi, T., Severinghaus, J. P. \& Kawamura, K. Argon and nitrogen isotopes of trapped air in the GISP2 ice core during the Holocene epoch (0-11,500 B.P.): Methodology and implications for gas loss processes. Geochim. Cosmochim. Acta 72, 4675-4686 (2008).

45. Lüthi, D. et al. $\mathrm{CO}_{2}$ and $\mathrm{O}_{2} / \mathrm{N}_{2}$ variations in and just below the bubble-clathrate transformation zone of Antarctic ice cores. EPSL 297, 226-233 (2010).

46. Neff, P. A review of the brittle ice zone in polar ice cores. Ann. Glaciol. 55, 72-82 (2014).

47. Taylor, K. C. \& Alley, R. B. WAIS Divide Ice Core Project: End of Season Field Reports 2007/2008 and 2008/2009. http://www.waisdivide.unh.edu/fieldreports

48. Severinghaus, J. P., Beaudette, R., Headly, M. A., Taylor, K. \& Brook, E. J. Oxygen-18 of $\mathrm{O}_{2}$ Records the Impact of Abrupt Climate Change on the Terrestrial Biosphere. Science 324, 1431-1434 (2009).

49. Souney, J. M. et al. Core handling and processing for the WAIS Divide ice-core project. Ann. Glaciol. (2014).

50. Bereiter, B., Schwander, J., Lüthi, D. \& Stocker, T. F. Change in $\mathrm{CO}_{2}$ concentration and $\mathrm{O}_{2} / \mathrm{N}_{2}$ ratio in ice cores due to molecular diffusion. Geophys. Res. Lett. 36, doi:10.1029/2008GL036737 (2009).

51. Schmitt, J. et al. Carbon Isotope Constraints on the Deglacial $\mathrm{CO}_{2}$ Rise from Ice Cores. Science 336, 711-714 (2012).

52. Wanninkhof, R. Relationship between wind speed and gas exchange over the ocean revisited. Limnol. Oceanogr. Methods 12, 351-362 (2014).

53. Keeling, R. F. et al. Measurement of changes in atmospheric $\mathrm{Ar} / \mathrm{N}_{2}$ ratio using a rapidswitching, single-capillary mass spectrometer system. Tellus 56B, 322-338 (2004).

54. Viglione, G. A. \& Thompson, A. F. Lagrangian pathways of upwelling in the Southern Ocean. J. Geophys. Res. Ocean. 121, 6295-6309 (2016).

55. Spahni, R. et al. The attenuation of fast atmospheric $\mathrm{CH}_{4}$ variations recorded in polar ice cores. Geophys. Res. Lett. 30, doi:10.1029/2003GL017093 (2003). 
1018 56. Snow, K., Sloyan, B. M., Rintoul, S. R., Hogg, A. M. \& Downes, S. M. Controls on

1019

1020

1021

1022

1023

1024

1025

1026

1027

1028

1029

1030

1031

1032

1033

1034

1035

1036

1037

1038

1039

1040

1041

1042

1043

1044

1045

1046

1047

1048

1049

1050

1051

1052

1053

1054

1055

1056

1057

1058

1059

1060

1061

1062 circulation, cross-shelf exchange, and dense water formation in an Antarctic polynya. Geophys. Res. Lett. (2016). doi:10.1002/2016GL069479

57. Schwander, J. Gas diffusion in firn. Chem. Exch. Between Atmos. Polar Snow. NATO ASI Ser. I 43, 527-540 (1996).

58. Kawamura, K. et al. Kinetic fractionation of gases by deep air convection in polar firn. Atmos. Chem. Phys. Discuss. 13, $7021-7059$ (2013).

59. Headly, M. A. PhD Thesis: Krypton and xenon in air trapped in polar ice cores: Paleoatmospheric measurements for estimating past mean ocean temperature and summer snowmelt frequency. University of California, San Diego (Scripps Institution of Oceanography, 2008).

60. Buizert, C. \& Severinghaus, J. P. Dispersion in deep polar firn driven by synoptic-scale surface pressure variability. Cryosph. (2016).

61. Hamme, R. C. \& Emerson, S. R. The solubility of neon, nitrogen and argon in distilled water and seawater. Deep. Res. I 51, 1517-1528 (2004).

62. Weiss, R. F. \& Kyser, T. K. Solubility of Krypton in Water and Seawater. J. Chem. Thermodyn. 23, 69-72 (1978).

63. Wood, D. \& Caputi, R. Solubilities of $\mathrm{Kr}$ and $\mathrm{Xe}$ in fresh and sea water. U.S. Naval Radiological Defense Laboratory, San Francisco, CA, 94135 (1966).

64. Schlatter, T. W. Atmospheric Composition and Vertical Structure. Article ID: eae31. (NOAA Earth Systems Research Laboratory, 2009).

65. Alduchov, O. a. \& Eskridge, R. E. Improved Magnus Form Approximation of Saturation Vapor Pressure. Journal of Applied Meteorology 35, 601-609 (1996).

66. He, F. et al. Simulating global and local surface temperature changes due to Holocene anthropogenic land cover change. Geophys. Res. Lett. 41, 1-7 (2014).

67. Allan, R. \& Ansell, T. A new globally complete monthly historical gridded mean sea level pressure dataset (HadSLP2): 1850-2004. J. Clim. 19, 5816-5842 (2006).

68. Jiang, D. \& Lang, X. Last glacial maximum East Asian monsoon: Results of PMIP simulations. J. Clim. 23, 5030-5038 (2010).

69. Sarmiento, J. L. \& Gruber, N. Ocean Biogeochemical Dynamics. (Princeton University Press, 2006).

70. Schmidt, G. A. et al. Using palaeo-climate comparisons to constrain future projections in CMIP5. Clim. Past 10, 221-250 (2014).

\section{Extended Data Legends}

Figure S1: Elements related to the gravitational and thermal correction applied to the ice core data.

a: Residual of the isotope data after correction for gravitational enrichment in the firn based on $\delta^{40} \mathrm{Ar}$ (orange) and modelled firn temperature gradients (b: green). In contrast to $\delta^{15} \mathrm{~N}$ (black), $\delta^{86} \mathrm{Kr}$ (purple) clearly deviates from the zero line by -56 per meg on average, showing that our correction factors for $\delta^{86} \mathrm{Kr}$ are over estimated $\left(\delta^{40} \mathrm{Ar}\right.$ is zero by definition because we use this data for the correction). Error bars represent the 1-sigma analytical uncertainty of our method based on repeated measurements of modern air samples ${ }^{10}$. b: The two independent WAIS divide ice core site firn temperature gradient scenarios used in this study. Green: modelled thermal gradient of ref. 36. Blue: Scenario derived based on our isotope records of $\delta^{15} \mathrm{~N}, \delta^{40} \mathrm{Ar}$ and $\delta^{86} \mathrm{Kr}$, while first we corrected $\delta^{86} \mathrm{Kr}$ by the offset seen in $\mathbf{a}$. 
1063 Figure S2: Raw atmospheric noble gas elemental ratios and the relative difference in the MOT

1064 signal they contain. a: Reconstructed atmospheric elemental ratios (orange $=\delta \mathrm{Kr} / \mathrm{N}_{2} ;$ red $=\delta \mathrm{Xe} / \mathrm{N}_{2}$;

1065

1066

1067

1068

1069

1070

1071

1072

1073

1074

1075

1076

1077

1078

1079

1080

1081

1082

1083

1084

1085

1086

1087

1088

1089

1090

1091

1092 purple $=\delta \mathrm{Xe} / \mathrm{Kr}$ ) using $\delta^{40} \mathrm{Ar}$ to correct for gravitational enrichment in the firn and the firn temperature gradient scenario based on our isotope data (see ED Fig. 1) to correct for thermal fractionation. The error bars represent the 1-sigma error as in ED Fig. 1 a. b: Differences between MOT derived from each of the three gas pairs relative to the best-estimate data (compare with Fig. 1 ; orange $=\mathrm{Kr} / \mathrm{N}_{2}-\mathrm{Mix}$, red $=\mathrm{Xe} / \mathrm{N}_{2}-\mathrm{Mix}$, purple $=\mathrm{Xe} / \mathrm{Kr}-\mathrm{Mix}$, ).

Table S1: The different elements considered in the box model and their effects on the LGMHolocene MOT difference. Sea-level change (SLC) effects are most important whereas also its subeffects are listed. The bottom three elements marked with * are not considered in our MOT record. See text in methods section for more details.

Table S2: Ocean and surface temperatures for LGM and Pre-industrial Control (PiC) conditions as simulated by 7 independent climate models. Mean Ocean Temperature (MOT) and Average Sea Surface Temperatures (ASST) are calculated by averaging the potential temperature fields in time and space of the corresponding experiments (see text for more details), while for ASST the sea ice covered area was excluded. Global Average Surface Temperature (GAST) is calculated by similar averaging of the corresponding air temperature fields. The values denoted with ${ }^{*}$ and * mark the highest and lowest value of the corresponding row, respectively. The "Ensemble Mean" column shows the average of the 7 models. The $\Delta \mathrm{GAST} / \triangle \mathrm{MOT}$ and $\Delta \mathrm{ASST} / \Delta \mathrm{MOT}$ scaling factors of the FGOALS model are rejected because former would suggest an unrealistically cold GAST for LGM of $11^{\circ} \mathrm{C}$ below today and both values are outliers with respect to the corresponding values of the other models. Detailed information about the individual models and the used output data can be found on any openly accessible data server node of the CMIP project. 


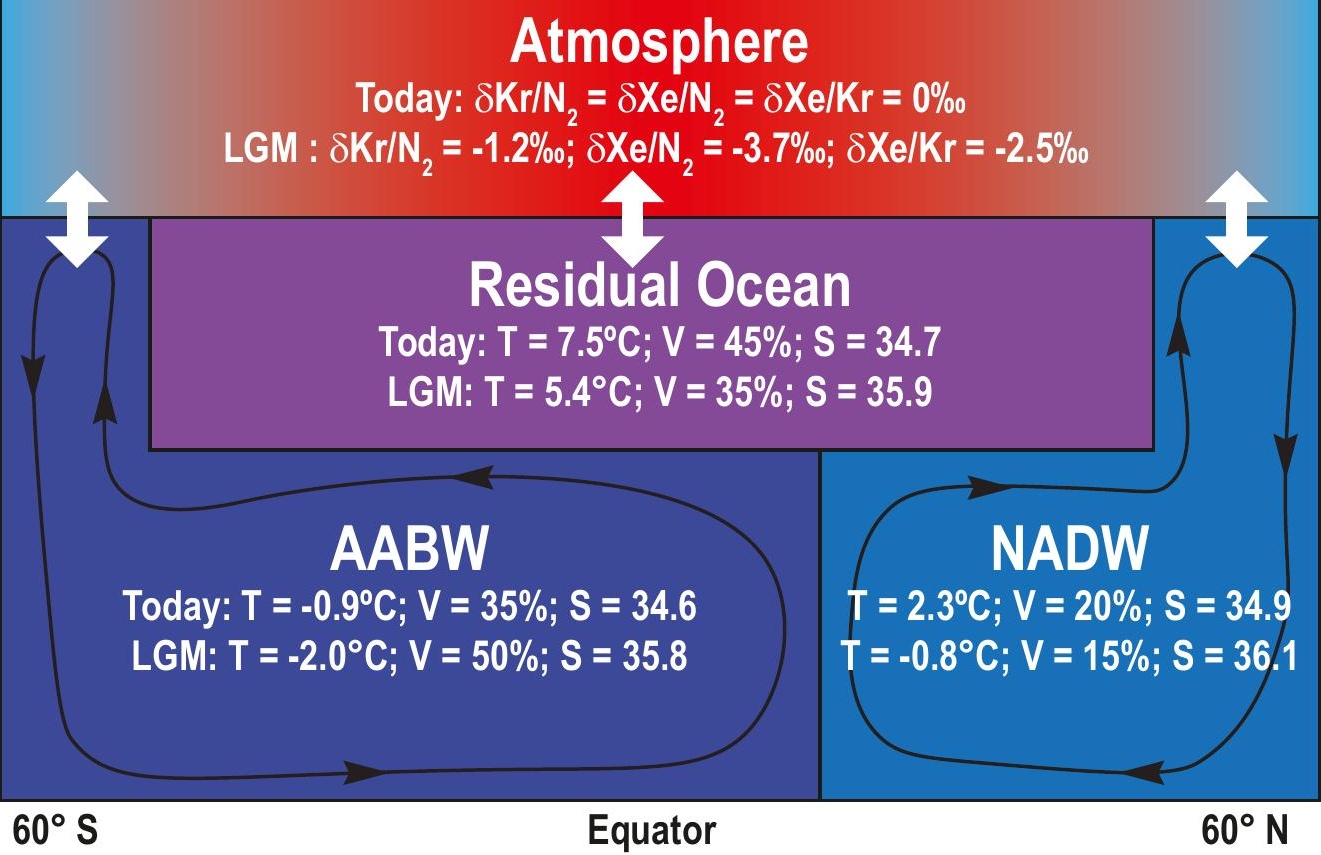




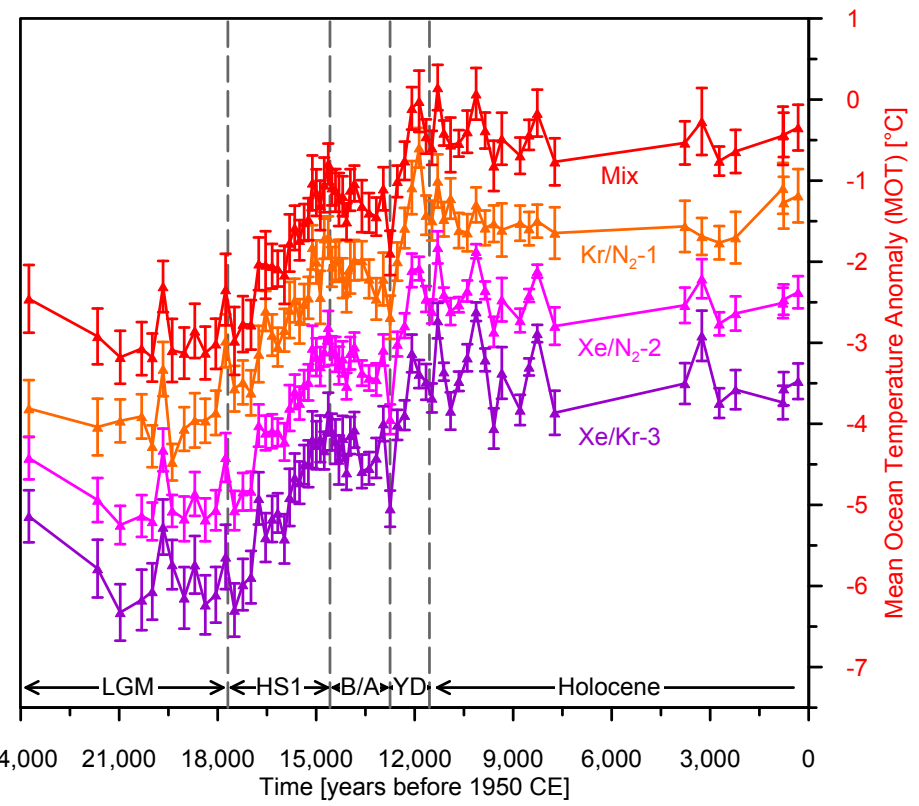




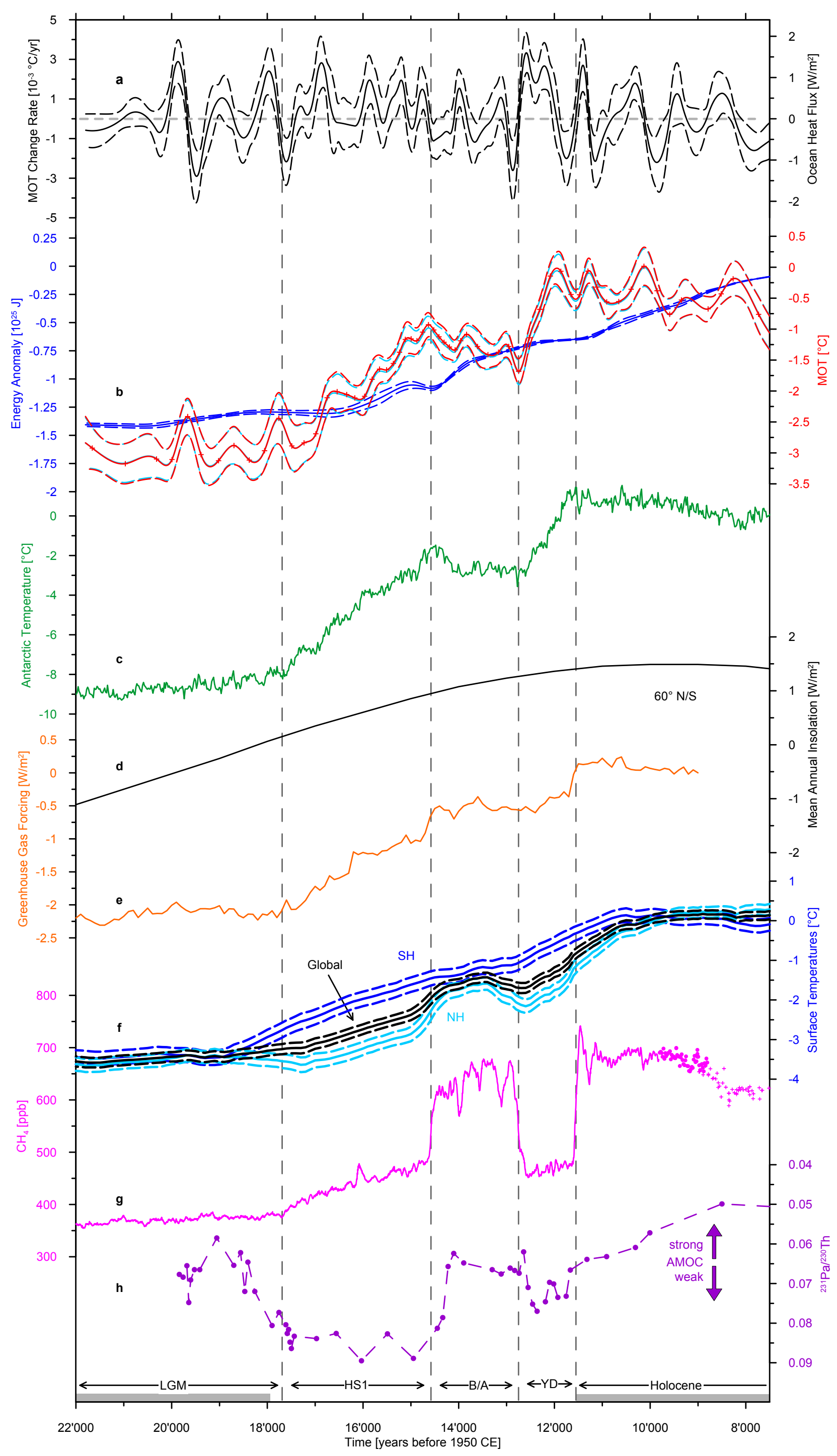




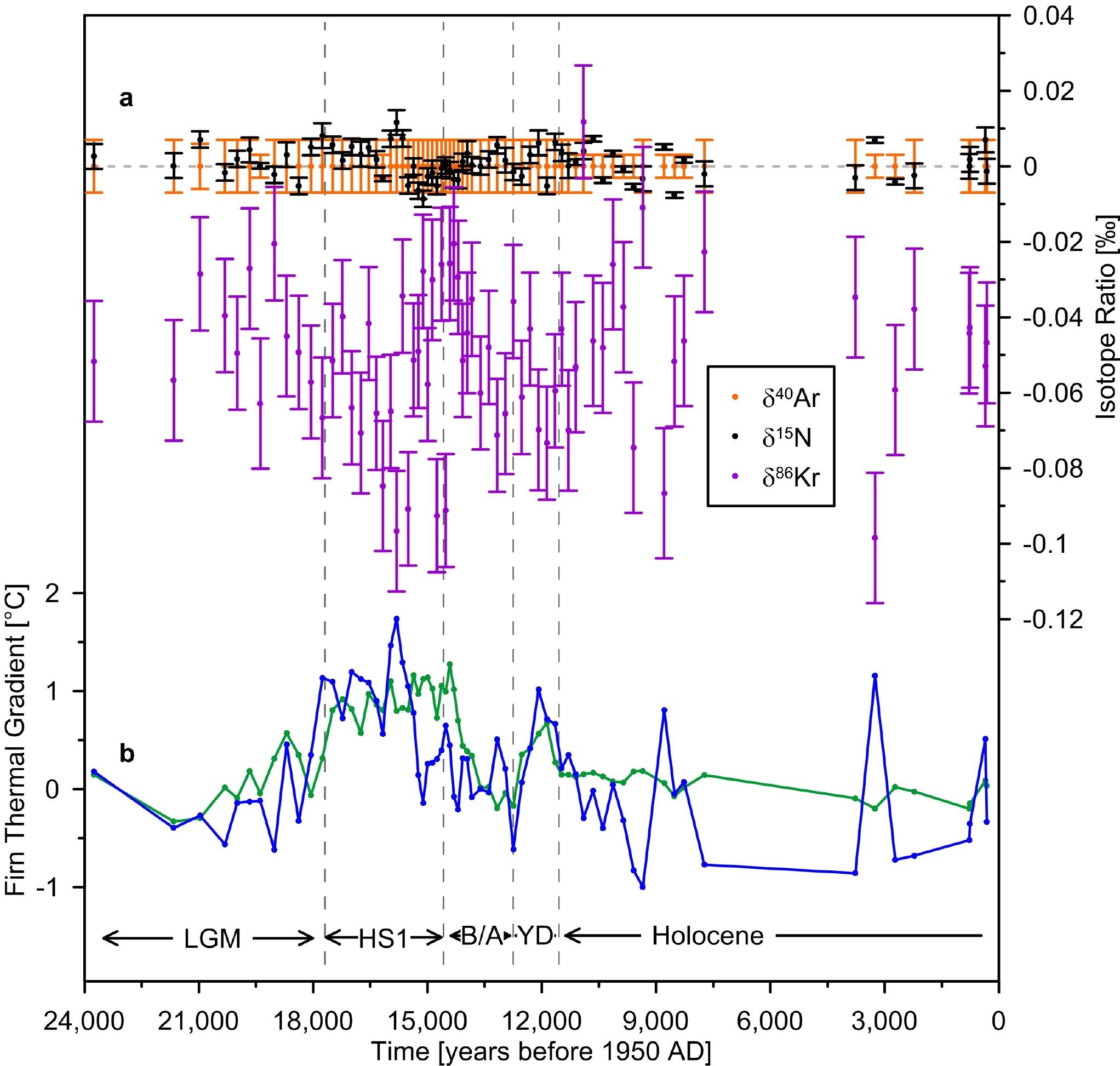




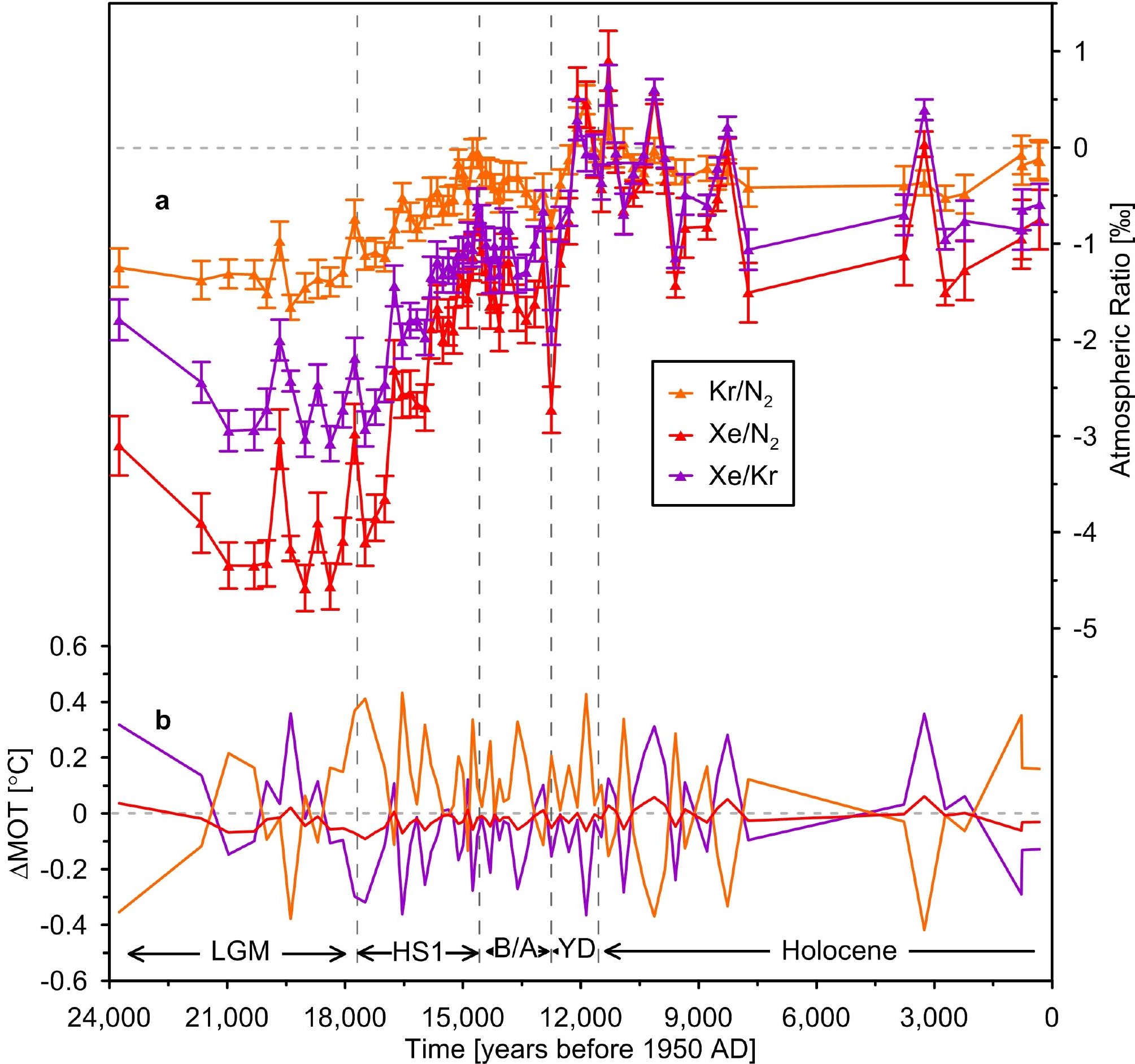


1 Table S1 - Mean Global Ocean Temperatures during the Last Glacial Transition

2 Authors: Bernhard Bereiter*1,2,3, Sarah Shackleton ${ }^{1}$, Daniel Baggenstos ${ }^{1,2}$, Kenji Kawamura ${ }^{4}$, Jeff 3 Severinghaus ${ }^{1}$

$4{ }^{1}$ Scripps Institution of Oceanography, University of California San Diego, La Jolla, California 5 92037, USA

$6{ }^{2}$ Climate and Environmental Physics and Oeschger Center for Climate Research, University of 7 Bern, 3012 Bern, Switzerland

$8{ }^{3}$ Laboratory for Air Pollution and Environmental Technology, Empa, 8600 Dübendorf, Switzerland

$9{ }^{4}$ National Institute of Polar Research, Research Organizations of Information and Systems, 10-3

10 Midori-cho, Tachikawa, Tokyo 190-8518, Japan.

$11 *$ Corresponding Author: bereiter@climate.unibe.ch

13 Effects of Model elements on LGM-Holocene MOT difference

\begin{tabular}{|c|c|c|}
\hline Model element & $\begin{array}{l}\text { LGM values relative to } \\
\text { Holocene }\end{array}$ & $\begin{array}{l}\text { Element specific effect on LGM- } \\
\text { Holocene MOT difference }\end{array}$ \\
\hline \multirow{3}{*}{ Noble Gases } & & $-1.8^{\circ} \mathrm{C}$ \\
\hline & $-2.5 \% 0(\mathrm{Xe} / \mathrm{Kr})$ & $-2.2^{\circ} \mathrm{C}$ \\
\hline & $-3.7 \% 0\left(\mathrm{Xe} / \mathrm{N}_{2}\right)$ & $-2.1^{\circ} \mathrm{C}$ \\
\hline SLC - sum of all effects & $-132 m$ & $-0.5^{\circ} \mathrm{C}$ \\
\hline SLC - volume & $-3.5 \%$ & $-0.6^{\circ} \mathrm{C}$ \\
\hline SLC - salinity & $+3.5 \%$ & $-0.2^{\circ} \mathrm{C}$ \\
\hline SLC - SSP & $+1.5 \%$ & $+0.3^{\circ} \mathrm{C}$ \\
\hline $\begin{array}{l}\mathrm{SSP} \text { related to } \mathrm{H} 2 \mathrm{O} \text { content } \\
\text { of atmosphere }\end{array}$ & $-0.04 \%$ & $<-0.02^{\circ} \mathrm{C}$ \\
\hline SSP in high latitudes & $\begin{array}{c}-3 \% \\
\text { (constant offset) }\end{array}$ & $-0.05^{\circ} \mathrm{C}$ \\
\hline $\mathrm{Kr}$ and $\mathrm{Xe}$ saturation state & $+50 \%$ & $\begin{array}{c}<+0.02^{\circ} \mathrm{C}\left(\mathrm{Kr} / \mathrm{N}_{2}\right) \\
+0.3^{\circ} \mathrm{C}\left(\mathrm{Xe} / \mathrm{N}_{2}\right) \\
+0.4^{\circ} \mathrm{C}(\mathrm{Xe} / \mathrm{Kr})\end{array}$ \\
\hline Non-freezing of $\mathrm{AABW}$ & - & $-0.2^{\circ} \mathrm{C}$ \\
\hline AABW volume & $+40 \%$ & $+0.1^{\circ} \mathrm{C}$ \\
\hline \multicolumn{2}{|c|}{ Total LGM-Holocene MOT change } & $2.57+/-0.24^{\circ} \mathrm{C}$ \\
\hline AABW salinity anomaly* & +1 PSS & $-0.02^{\circ} \mathrm{C}$ \\
\hline Floating ice shelf volume* & $+2.6 \mathrm{e} 15 \mathrm{~m}^{3}$ & $-0.1^{\circ} \mathrm{C}$ \\
\hline $\begin{array}{l}\text { Xe solubility function } \\
\text { correction* }\end{array}$ & $\begin{array}{c}+2 \% \\
\text { (constant offset) }\end{array}$ & $\begin{array}{l}+0.04^{\circ} \mathrm{C}\left(\mathrm{Xe} / \mathrm{N}_{2}\right) \\
+0.07^{\circ} \mathrm{C}(\mathrm{Xe} / \mathrm{Kr})\end{array}$ \\
\hline
\end{tabular}


1 Table S2 - Mean Global Ocean Temperatures during the Last Glacial Transition

2 Authors: Bernhard Bereiter* ${ }^{1,2,3}$, Sarah Shackleton ${ }^{1}$, Daniel Baggenstos ${ }^{1,2}$, Kenji Kawamura ${ }^{4,5,6}$, Jeff 3 Severinghaus ${ }^{1}$

$4{ }^{1}$ Scripps Institution of Oceanography, University of California San Diego, La Jolla, California

592037, USA

$6{ }^{2}$ Climate and Environmental Physics and Oeschger Center for Climate Research, University of

7 Bern, 3012 Bern, Switzerland

$8 \quad{ }^{3}$ Laboratory for Air Pollution and Environmental Technology, Empa, 8600 Dübendorf, Switzerland

$9{ }^{4}$ National Institute of Polar Research, Research Organizations of Information and Systems, 10-3

10 Midori-cho, Tachikawa, Tokyo 190-8518, Japan.

$11{ }^{5}$ Department of Polar Science, Graduate University for Advanced Studies (SOKENDAI), 10-3

12 Midori-cho, Tachikawa, Tokyo 190-8518, Japan.

$13{ }^{6}$ Institute of Biogeosciences, Japan Agency for Marine-Earth Science and Technology, 2-15

14 Natsushima-cho, Yokosuka 237-0061, Japan.

*Corresponding Author: bereiter@climate.unibe.ch

\begin{tabular}{|l|c|c|c|c|c|c|c|c|}
\hline & Bern3D & $\begin{array}{c}\text { CNRM- } \\
\text { C5 }\end{array}$ & CCSM4 & FGOALS & MIROC & MPI & MRI & $\begin{array}{c}\text { Ensemble } \\
\text { Mean }\end{array}$ \\
\hline MOT PiC & 4.02 & 4.24 & $3.21^{*}$ & 3.68 & 4.13 & $4.94^{\#}$ & 4.24 & $\mathbf{4 . 0 7}$ \\
\hline GAST PiC & $15.28^{\#}$ & 13.20 & 13.33 & $12.43^{*}$ & 13.60 & 13.64 & 13.59 & $\mathbf{1 3 . 5 8}$ \\
\hline ASST PiC & 19.51 & 18.94 & $19.75^{\#}$ & 18.84 & 18.75 & $18.50^{*}$ & 19.59 & $\mathbf{1 9 . 1 3}$ \\
\hline MOT LGM & 2.32 & $3.32^{\#}$ & $1.26^{*}$ & 2.59 & 2.42 & 3.03 & 2.31 & $\mathbf{2 . 4 6}$ \\
\hline GAST LGM & $11.94^{\#}$ & 10.57 & 8.42 & $7.70^{*}$ & 8.60 & 9.23 & 8.91 & $\mathbf{9 . 3 4}$ \\
\hline ASST LGM & 18.05 & 18.16 & $18.28^{\#}$ & $16.81^{*}$ & 17.22 & 17.22 & 17.96 & $\mathbf{1 7 . 6 7}$ \\
\hline$\triangle$ ASST/ $\triangle \mathrm{MOT}$ & 0.86 & 0.85 & 0.75 & $\left(1.86^{\#}\right)$ & 0.89 & $0.67^{*}$ & 0.84 & $\mathbf{0 . 8 0}$ \\
\hline$\triangle \mathrm{GAST} / \triangle \mathrm{MOT}$ & $1.96^{*}$ & 2.86 & 2.52 & $\left(4.34^{\#}\right)$ & 2.92 & 2.31 & 2.42 & $\mathbf{2 . 5 0}$ \\
\hline
\end{tabular}

